\title{
DEJAR DE JUGAR POR LAS REGLAS: HACIA UNA REVITALIZACIÓN DEL DERECHO SOCIETARIO COMO INSTRUMENTO DE POLÍTICA ECONÓMICA
}

\author{
Ignacio Valenzuela Nieto \\ Pontificia Universidad Católica de Chile
}

\begin{abstract}
Resumen: Para abordar los conflictos de agencia que se generan entre socios mayoritarios y minoritarios en las organizaciones de negocios, algunas jurisdicciones han optado por sistemas de control ex ante, basados en prohibiciones y reglas de autocumplimiento, mientras otras han preferido sistemas de control ex post, en los que predominan los estándares. El legislador chileno, consciente de una propiedad concentrada y falta de experiencia institucional en la materia, optó por privilegiar un sistema de control ex ante. Este sistema, aunque cumple algunos de los objetivos pretendidos, hoy dificulta el desarrollo y evolución dinámica del derecho societario nacional. En este artículo se plantean las ventajas de apuntar hacia un sistema mixto que favorezca los estándares y, siguiendo un precedente lati-
\end{abstract}

Ignacio Valenzuela Nieto. Abogado de la Pontificia Universidad Católica de Chile. Máster por Columbia University. Investigador asociado del Centro de Estudios Internacionales UC e investigador del David Rockefeller Center for Latin American Studies (DRCLAS) en Harvard University. Email: ignacio_valenzuela@uc.cl.

El autor agradece la colaboración de Lucas Sierra, José Miguel Mendoza y Aurelio Gurrea Martínez, así como los valiosos comentarios de dos árbitros anónimos de Estudios Públicos. Cualquier error que pueda contener el artículo, declara, es de su exclusiva responsabilidad. 
noamericano, se sugieren principios para implementarlo de manera exitosa.

Palabras Clave: derecho societario, sociedades comerciales, gobiernos corporativos, problemas de agencia.

RECIBIDO: enero 2019; ACEPTADO: abril 2019.

Clasificación JEL: G32; G38; K20; K41.

\section{QUIT PLAYING BY THE RULES: TOWARDS A REVITALIZATION OF CORPORATE LAW AS AN INSTRUMENT OF ECONOMIC POLICY}

ABSTRACT: To deal with agency conflicts that arise between majority and minority shareholders in business organizations, some jurisdictions have opted for ex ante control systems, based on bans and self-enforcing rules, while others have preferred ex post control systems, in which the standards predominate. The Chilean legislator, aware of a concentrated property and lack of institutional experience in the matter, chose to favor an ex ante control system. Such system, although fulfills some of its purposes, hinders the dynamic development and evolution of Chilean corporate law. This article presents the advantages of pointing towards a mixed system that prefers standards and, following a Latin American precedent, suggests principles for its successful implementation.

KEYwords: corporate law, business organizations, corporate governance, agency problems.

RECEIVED: January 2019; ACCEPTED: April 2019.

JEL Classification: G32; G38; K20; K41.

\section{INTRODUCCIÓN}

a protección de la propiedad privada ha sido consistentemente en

la modernidad un pilar fundamental del desarrollo económico de las naciones. Este patrón comenzó a hacerse particularmente relevante hacia fines de la Edad Media. En la época de las exploraciones y los grandes navegantes, el éxito de las empresas de conquista en levantar capital dependía (digiérase, las primeras sociedades por acciones de la historia), en buena parte, de la protección que ofrecían sus reinos a la propiedad privada y el imperio del derecho. ${ }^{1}$

${ }^{1}$ Por ejemplo, en el siglo XVI, Holanda, tierra pequeña, pantanosa y carente de recursos naturales, arrebató a España, entonces el reino más poderoso de Europa 
En términos de la propiedad recaída sobre las personas jurídicas, la adecuada protección de los activos de los inversionistas — los valores o títulos que reflejan su participación en la respectiva sociedad, junto con los derechos aparejados a dicha propiedad - se traduce en consecuencias positivas para el desarrollo económico. Dentro de estas consecuencias se encuentran una mayor demanda por los valores o títulos representativos del capital aportado, condiciones más favorables para quienes buscan financiamiento por vía de capital (los emprendedores y empresarios), más empresas que buscan financiarse por dicha vía, mayor liquidez de las inversiones, mayor madurez y profundidad de los mercados de capitales y, como corolario, mejores condiciones para el emprendimiento, más respaldo a la innovación y un mayor desarrollo de las organizaciones, empresas y mercados. Ello, a su vez, puede reflejarse en una mayor generación de riquezas y más y mejores puestos de trabajo, lo que repercute en el bienestar de todos los ciudadanos.

A fines de los años noventa, La Porta y López-de-Silanes, junto con otros, concluyeron que los países con protección deficiente de los accionistas minoritarios, medida tanto por la calidad de las normas legales como por la ejecución de las mismas, tienen en general mercados de capitales más pequeños y menos desarrollados. ${ }^{2}$ Siguiendo estos estudios, organismos internacionales como el Banco Mundial y la OCDE se abocaron a desarrollar recomendaciones sobre gobernanza corporativa para Latinoamérica, con la motivación de que las medidas recomendadas, de ser implementadas, ayudarían a los países de la región a mejorar sus mercados de capitales. Chile fue uno de los que promovieron reformas a su marco legal societario observando estas recomendaciones.

Si bien Chile hoy obtiene buenos resultados en mediciones de organismos multinacionales sobre reglas de protección de inversionis-

y que dominaba un imperio global, el control de las rutas de comercio. Esto lo logró, principalmente, ganando la confianza de los inversionistas en base al pago íntegro y oportuno de sus deudas y un sistema judicial que gozaba de independencia y protegía los derechos individuales; en particular, los derechos de propiedad. Las certezas generadas por tal sistema, de paso, convirtieron a Ámsterdam en el centro financiero de Europa. Ver Yuval Noah Harari, Sapiens (New York: Harper Collins, 2015), 318.

2 Ver La Porta et al., "Law and Finance", Journal of Political Economy 106, n. ${ }^{\circ} 6$ (1998) y La Porta et al., "Investor Protection and Corporate Governance", Journal of Financial Economics 58 (2000). 
tas minoritarios (en comparación con sus pares latinoamericanos), ${ }^{3} \mathrm{su}$ marco legislativo ha obstado a que el derecho societario se convierta en una herramienta de política económica relevante. ${ }^{4}$ Como consecuencia de lo anterior, sumado a altos niveles de concentración de la propiedad, existen mayores riesgos de que conductas oportunistas por parte de los accionistas mayoritarios causen perjuicios a los minoritarios (incluyendo inversionistas institucionales) y a la sociedad en cuestión. La falta de certezas de los inversionistas acerca de si el controlador de la sociedad objeto de inversión incurrirá o no en dichas conductas genera problemas de selección adversa, haciendo así más costoso el levantamiento de capital y obstando al mejor desarrollo económico del país.

Este documento expone los problemas que genera el riesgo de expropiación por parte de los accionistas mayoritarios y distingue entre los sistemas de protección de accionistas basados en reglas — como el chileno- - y aquellos basados en estándares. A continuación, se explican las fortalezas y debilidades de cada sistema, argumentando por qué, en consideración a las circunstancias particulares de Chile actual, sería preferible un sistema de protección mixto que, de manera gradual, favorezca los estándares; aun cuando ello supone desafíos importantes en su implementación. Finalmente, se plantean las consideraciones legales y de política pública que podrían contribuir a que el país lleve adelante de manera exitosa una transición hacia un sistema que considere estándares, para la prevención y resolución de conflictos societarios.

${ }^{3}$ Según el ranking de la Asociación Latinoamericana de Private Equity y Venture Capital (LAVCA, por su sigla en inglés), Chile junto a Brasil, Colombia y México tienen los puntajes más altos de la región en el ítem protección de derechos de los accionistas minoritarios. Ver Latin America Private Equity y Venture Capital Association, 2017/2018 Scorecard: The Private Equity and Venture Capital Environment in Latin America (New York: Latin America Private Equity y Venture Capital Association, 2017), 4. Disponible en https://avca.org/wp-content/ uploads/2017/06/20172018-Scorecard-FINAL.pdf.

${ }^{4}$ Según el ranking Doing Business, elaborado por el Banco Mundial, es mucho lo que Chile puede todavía mejorar en aspectos tan relevantes para el desarrollo de los mercados, como facilidad de los accionistas para demandar, calidad de las reglas que determinan las estructuras de control y cambios en el control de las compañías, transparencia en la información societaria, y calidad del proceso judicial. En todos estos aspectos, Chile se ubica bajo el promedio en la categoría de altos ingresos de la OCDE. Ver World Bank Group, Doing Business 2019: Training for Reform. Economy Profile: Chile (Washington DC: International Bank for Reconstruction and Development/The World Bank, 2019), 33 y 46. Disponible en http:// www.doingbusiness.org/content/dam/doingBusiness/country/c/chile/CHL.pdf. 


\section{EL PROBLEMA DE LA EXPROPIACIÓN POR PARTE DE LOS ACCIONISTAS MAYORITARIOS}

En términos generales, son tres los tipos de problemas de agencia que se generan en las organizaciones de negocios:

i) Conflictos entre la empresa y sus administradores contratados;

ii) Conflictos entre accionistas controladores o mayoritarios y accionistas no controladores o minoritarios, $\mathrm{y}$

iii) Conflictos entre la empresa y otras partes con la que la misma contrata (como acreedores, empleados y clientes). ${ }^{5}$

De estos problemas de agencia, aquellos entre accionistas mayoritarios y minoritarios son los que prevalecen en Latinoamérica, ${ }^{6}$ incluyendo Chile. Esto es consecuencia del alto nivel de concentración de la propiedad que existe en las sociedades de la región, lo que, en el caso de Chile, se refleja en la presencia habitual de accionistas controladores en las sociedades constituidas en el país. ${ }^{7}$ Tales accionistas controladores

${ }^{5}$ Reinier Kraakman et al., The Anatomy of Corporate Law: A Comparative and Functional Approach (New York: Oxford University Press, 2017), 29-30.

${ }^{6}$ Resaltando este aspecto, ver Aurelio Gurrea Martínez y Oliver Orton, "Hacia un sistema creíble de directores independientes en las sociedades cotizadas latinoamericanas", Instituto Iberoamericano de Derecho y Finanzas Working Paper Series 3/2018 (2018): 4-5, https://papers.ssrn.com/sol3/papers.cfm?abstract_id=3144054, y Francisco Reyes Villamizar, "Corporate Governance in Latin America: A Functional Analysis", University of Miami Inter-American Law Review 39 (2008): 207-268. Disponible en https://repository.law.miami.edu/umialr/vol39/ iss $2 / 2 /$.

${ }^{7}$ Si bien no existe evidencia sistemática a través del tiempo, una serie de estudios proveen información relevante al respecto. En uno de los estudios más citados en la materia, se indica que para el año 2002, en una muestra de 260 sociedades chilenas, el mayor accionista tenía, en promedio, el 55 por ciento de la propiedad. El mismo estudio revela que, para ese mismo año y universo de sociedades, los cinco mayores accionistas tenían, en promedio, el 80 por ciento de la propiedad. Ver Fernando Lefort, "Ownership Structure and Corporate Governance in Latin America”, Revista Abante 8, n. 1 (2005): 64. Disponible en http://finanzas.udp.cl/paper/ f117\%20OWNERSHIP\%20STRUCTURE\%20AND\%20CORPORATE\%20GOVERNANCE\%20IN\%20LATIN\%20AMERICA.pdf. En el año 2009, el controlador medio en las sociedades anónimas abiertas poseía el 67 por ciento de la propiedad, mientras que menos del 1 por ciento de las mismas hubieran sido consideradas como de "propiedad dispersa" al aplicar los umbrales comúnmente considerados en la literatura especializada. Ver Marcelo Donelli et al., "Ownership Dynamics with Large Shareholders: an Empirical Analysis", Journal of Financial and Quantitative Analysis 48 (2013): 8: Disponible en https://ssrn.com/abstract=1966011. Adicional- 
ejercen control efectivo sobre los gerentes y otros administradores sociales (por la vía de designación, remoción y monitoreo permanente), así como, consecuencialmente con lo anterior, sobre las relaciones de la empresa con otras partes con las que la misma contrata. Como resultado, disminuyen los problemas de agencia subyacentes a ambos tipos de relaciones. A pesar de tales ventajas, la presencia de accionistas de control genera riesgos de expropiación (o tunneling) para los accionistas minoritarios, dando lugar a problemas de agencia relevantes entre éstos y aquéllos. ${ }^{8}$ Esto se debe a que el accionista controlador eventualmente buscará la manera más eficiente de despojar a los accionistas minoritarios para su propio beneficio, sea por la vía de apropiarse de flujos de caja (reduciendo la disponibilidad de caja sin afectar los activos operacionales, como otorgar préstamos a partes relacionadas en condiciones más favorables que las ofrecidas por el mercado o realizar pagos excesivos a los miembros del directorio), activos fijos (vendiendo a partes relacionadas activos subvalorados), porcentajes de participación (diluyendo culposa o dolosamente la participación de un minoritario), ${ }^{9} \mathrm{u}$ oportunidades de negocios (tomándolas, directa o indirectamente, para sí, en desmedro de la sociedad controlada). ${ }^{10}$

Estos riesgos de expropiación, naturales en cualquier contexto donde existan accionistas de control, generan problemas de selección adversa. Tales problemas se reflejan en que, dado que los minoritarios

mente, en un análisis empírico de 119 compañías no financieras que transan sus acciones en la Bolsa de Comercio de Santiago entre los años 2002 y 2014, se observa que, en promedio, el 43 por ciento de las acciones en circulación se encuentran en manos del accionista controlador (lo que excede largamente el porcentaje necesario para ejercer control). A mayor abundamiento, dentro de ese mismo periodo se observa que el 52 por ciento de las empresas estudiadas se encuentran relacionadas a uno de los grandes grupos económicos del país. Estas empresas consistentemente han exhibido mayor concentración en la propiedad por el accionista mayoritario. Ver Paolo Saona et al., "Group Affiliation and Ownership Concentration as Determinants of Capital Structure Decisions: Contextualizing the Facts for an Emerging Economy", Emerging Markets Finance and Trade (2017): 4, 7. Disponible en doi: 10.1080/1540496X.2017.1392850.

${ }^{8}$ Ver Alfredo Enrione, "Gobierno corporativo: un imperativo de hoy", en Directorio y gobierno corporativo: el desafio de agregar valor en forma sostenida, editado por Alfredo Enrione (Santiago: ESE Business - Universidad de los Andes, 2014), 34-36.

9 José Miguel Mendoza, "El abuso de mayoría en la SAS”, en La SAS y su influencia en América Latina, editado por Francisco Reyes (Bogotá: Editorial Temis, 2018), 118-119.

${ }^{10}$ Enrione, "Gobierno corporativo", 35-36. 
desconocen ex ante si serán o no objeto de expropiación o si podrán o no encontrar remedios adecuados en caso de que ello ocurra, aumentan los costos del financiamiento empresarial por vía de capital (y, eventualmente, del financiamiento externo, en general).

\section{ADECUACIÓN DE LOS SISTEMAS LEGALES A LA REALIDAD}

El diseño de sistemas legales se inserta dentro de una de las problemáticas generales del derecho. Desde un punto de vista teórico, requiere una elección en un continuo cuyos extremos son los estándares y las reglas - o en lenguaje de Dworkin, principios y reglas - , como elementos medulares de disposición normativa. Dicha elección entre principios y reglas es esencial en la planificación de sistemas para regular la conducta humana. Dworkin planteaba que la diferencia entre principios legales y reglas legales es una distinción lógica. Así, tanto unos como otros apuntan a decisiones sobre obligaciones legales en circunstancias particulares, pero difieren en el carácter de la instrucción que proveen: mientras las reglas se aplican en un modo "todo o nada" (configurados los supuestos la regla debe aplicarse, a menos que sea inválida), los principios no proporcionan consecuencias legales específicas que deben ocurrir automáticamente ante la existencia de ciertas condiciones y requieren una ponderación de los mismos principios en forma previa a su aplicación. ${ }^{11}$ Existen grados en la designación de una norma como estándar o como regla y existirán así estándares que se asemejen a reglas y reglas que se asemejen a estándares. A medida que existe una mayor cantidad de estados posibles o mayor incertidumbre sobre las circunstancias que se relacionarán a la conducta prevista, el uso de principios sobre reglas se hace más conveniente. De tal manera, existe entre principios y reglas una tensión natural: los principios otorgan mayor dinamismo y la posibilidad de evolución ante estados del mundo inciertos (sin necesidad de modificaciones legislativas) al costo de menor previsibilidad en los resultados; las reglas otorgan mayores certezas en los resultados al costo de soluciones predeterminadas que son rígidas e inmutables, quizás ineficientes una vez conocidas las circunstancias que generan su

${ }^{11}$ Ronald M. Dworkin, "The Model of Rules", The University of Chicago Law Review 35 (1967): 25-27. 
aplicación. En cualquier caso, el costo de imprevisibilidad asociada a los principios disminuirá en la medida en que se desarrolle una experiencia institucional y criterios consistentes en su aplicación. El costo de inflexibilidad e ineficiencia de las reglas puede suplirse agregando reglas cada vez más específicas o modificando las reglas existentes, con los nuevos costos (principalmente transaccionales) que ello implica.

El derecho chileno ha incorporado tanto estándares como reglas en su diseño normativo. Así, por ejemplo, las normas sobre la sucesión intestada (título II del Libro Tercero del Código Civil), el contrato de arrendamiento (título XXVI del Libro Cuarto del Código Civil) y las del tránsito (Ley 18.290 , de 1984) se asemejan a reglas. Por otro lado, las normas sobre graduación de la culpa (art. 44 del Código Civil), el mandato a las entidades inscritas en el Registro de Valores que lleva la Comisión para el Mercado Financiero de "divulgar en forma veraz, suficiente y oportuna, todo hecho o información esencial respecto de ellas mismas y de sus negocios" (art. 10 de Ley 18.045, de 1981), y las disposiciones que sancionan "cualquier hecho, acto o convención que tienda a impedir la libre competencia" (art. 1 de Decreto Ley 211, de 1973) se asemejan a estándares.

En la práctica, no hay un sistema legal único que satisfaga de la mejor manera las necesidades de los distintos países. El sistema óptimo dependerá, entre otros factores, de la materia que se intente regular, la robustez del aparato estatal, la fortaleza de las instituciones judiciales y de la disponibilidad de recursos humanos y materiales adecuados.

Según Gilson y Schwartz, las reglas son más efectivas cuando hay pocos estados del mundo posibles; esto es, cuando abundan las certezas. Indican que esta condición, común en negocios jurídicos como la compraventa, es mucho más difícil de satisfacer cuando los estados del mundo se vinculan a la administración de una organización de negocios. Por esto, concluyen, hay una visión general de que las cortes deben regular las conductas vinculadas a decisiones de negocios - que implican evolución rápida y alto nivel de incertidumbre - por referencia a principios o estándares de conducta. ${ }^{12}$

12 Ronald J. Gilson y Alan Schwartz, "Constraints on Private Benefits of Control: Ex Ante Control Mechanisms Versus Ex Post Transaction Review", Yale Law \& Economics Research Paper 455; Stanford Law and Economics Olin Working Paper 432; Columbia Law and Economics Working Paper 430; ECGI - Law Working Paper 194/2012: 28. Disponible en http://dx.doi.org/10.2139/ssrn.2129502. 
La elección entre sistemas basados en estándares o en reglas, común a cualquier sistema jurídico, aplica también a los sistemas de control o revisión de actuaciones societarias. Éstos pueden caracterizarse, a grandes rasgos, de la siguiente manera (si bien, en la práctica, las regulaciones societarias no son enteramente de una u otra forma y serán más bien una combinación de ambos sistemas con predominancia de uno de ellos):

i) De control ex ante: Es un sistema basado en reglas. El legislador ha establecido prohibiciones o reglas de autocumplimiento (self-enforcing rules) para regular las actuaciones de los accionistas, directores y administradores ligados a una sociedad. El diseño de política pública de estas medidas privilegia una intervención estatal mínima previo a que tenga lugar la conducta en cuestión, en lugar de revisar, con posterioridad a la actuación, si la misma ha sido legítima. El ejemplo más evidente de estos mecanismos son los procedimientos para la aprobación de transacciones con partes relacionadas, en los que se suele requerir una combinación de requisitos que incluyen la aprobación por directores no conflictuados, acuerdo de mayorías calificadas de los accionistas o apreciación por peritos. Este mecanismo puede ir acompañado de un catálogo de operaciones que serán consideradas sujetas al mismo. Otros ejemplos de prohibiciones y reglas de autocumplimiento son el requisito de apreciación por peritos en otras operaciones vinculadas a la sociedad, los derechos de suscripción preferente en la emisión de nuevas acciones, el derecho a retiro que asiste a los accionistas minoritarios en caso de que se adopten ciertas decisiones definidas por el legislador, la obligación de distribuir un porcentaje establecido de dividendos y una descripción de los requisitos que deben cumplir los directores independientes para su designación.

ii) De control ex post: Es un sistema basado en estándares. Existe amplia libertad para que los accionistas, directores y administradores ligados a una sociedad adopten decisiones que estiman convenientes para la conducción de la entidad, sin que estén constreñidos por prohibiciones o reglas de autocumplimiento. El diseño de política pública de este sistema privilegia la intervención estatal a requerimiento de parte y de manera posterior a la actuación. La aplicación de este tipo de control requiere el desarrollo de estándares (basados en deberes fiduciarios y principios de equidad) que sirvan de base a la revisión de transaccio- 
nes ex post, siendo lo suficientemente concretos para servir de guía a quienes resuelvan las controversias y lo suficientemente amplios para permitir discrecionalidad en su aplicación para el caso particular. Dichos estándares impactarán el comportamiento futuro de los actores relevantes.

De la descripción anterior, puede concluirse que un sistema de control ex ante es preferible en países con una institucionalidad administrativa y judicial más débil, mientras que un sistema de control ex post funcionará mejor en jurisdicciones con un sistema administrativo y judicial más desarrollado y que ofrezca certeza en la ejecución de las sentencias. ${ }^{13}$ De manera semejante y, en principio, resulta natural que países con presencia mayoritaria de accionistas controladores — presumiblemente conducentes a mercados de valores menos profundos, dinámicos y desarrollados- opten por un modelo de control ex ante (pues, en principio, impone menores costos al aparato estatal), mientras que países donde la estructura de propiedad es más dispersa — presumiblemente conducentes a mercados de valores más sofisticados- se inclinen por un modelo de control ex post (pues los mayores costos impuestos al aparato estatal estarán mejor justificados).

\section{EL CASO DE CHILE}

Como se ha indicado, la estructura de capital societario en Chile es mayoritariamente concentrada, lo que incrementa los riesgos de que existan conductas expropiatorias de los accionistas mayoritarios en perjuicio de los minoritarios. A ese escenario se suma un escaso desarrollo jurisprudencial en cuanto a la resolución de controversias societarias, limitados recursos para la ejecución efectiva de acuerdos

${ }^{13}$ En este sentido, Black y Kraakman indican que las "economías desarrolladas usualmente tienen instituciones sofisticadas para hacer valer el cumplimiento de las normas; instituciones que pueden implementar reglas complejas, finamente matizadas. Las economías emergentes tienen instituciones menos sofisticadas para hacer valer el cumplimiento de las normas y, en consecuencia, necesitan reglas más simples y de mayor facilidad en su administración". Bernard Black y Reinier Kraakman, "A Self-Enforcing Model of Corporate Law", Harvard Law Review 109 (1996): 1925. 
entre particulares y una tradicional aversión a judicializar los conflictos societarios.

Motivado por la alta concentración en la propiedad, las tendencias internacionales de fines de la década de los setenta ${ }^{14} \mathrm{y}$, presumiblemente, la falta de experiencia en el tratamiento de conflictos societarios, el legislador nacional consagró en la Ley 18.046 (la "Ley sobre Sociedades Anónimas") un sistema de control ex ante, con un marcado predominio de prohibiciones y reglas de autocumplimiento, como las recién descritas. ${ }^{15}$

El sistema originalmente implementado por la Ley sobre Sociedades Anónimas fue reforzado con las reformas introducidas a partir del año 2000. Siguiendo recomendaciones de organizaciones internacionales en materias de gobierno corporativo, Chile modificó sucesivamente la regulación de sociedades, principalmente la Ley sobre Sociedades Anónimas, para aumentar los resguardos a los accionistas minoritarios. Fue así como, entre otras materias, se incorporó una acción derivativa (habilitando a los accionistas minoritarios para demandar en representación de la sociedad), ${ }^{16}$ un mecanismo para llevar adelante una oferta

${ }^{14}$ República de Chile, "Mensaje de la Ley 18.046”, 30 de diciembre de 1980. Disponible en https://www.bcn.cl/historiadelaley/nc/historia-de-la-ley/7574/.

${ }^{15}$ La Ley sobre Sociedades Anónimas, en su forma actual, contiene abundantes ejemplos de prohibiciones y reglas de autocumplimiento, incluyendo los siguientes artículos: 15 (aportes no consistentes en dinero deben ser estimados por peritos); 25 (derecho de suscripción preferente de nuevas acciones emitidas por aumento de capital); 44 (descripción de transacciones que califican como "operaciones con partes relacionadas" para sociedades anónimas cerradas y procedimiento de aprobación, el que incluye aprobación por directores no interesados o aprobación en junta de accionistas por supramayoría); 50 bis (requisito de nombrar directores independientes y comité de directores en ciertas sociedades anónimas abiertas, junto con descripción de personas que no se considerarán "independientes" para ser designadas en el cargo de director que tenga esa calidad); 69 (acuerdos que dan origen al derecho a retiro); 79 (en sociedades anónimas abiertas, dividendo mínimo obligatorio de 30 por ciento de utilidades líquidas del ejercicio salvo acuerdo unánime de accionistas); 146 (descripción de transacciones que califican como "operaciones con partes relacionadas" para sociedades anónimas abiertas), y 147 (procedimiento de aprobación de operaciones con partes relacionadas en sociedades anónimas abiertas, el que incluye aprobación por directores no interesados y, de ser el caso, aprobación en junta de accionistas por supramayoría, previo informe por peritos).

${ }^{16}$ Ver Ley 19.705, del 20 de diciembre de 2000, "Regula las ofertas públicas de adquisición de acciones (OPAS) y establece régimen de gobiernos corporativos", República de Chile. 
pública de adquisición de acciones cuando se pretenda superar cierto porcentaje en la propiedad de una sociedad anónima abierta (incluido en la Ley 18.045, de Mercado de Valores), ${ }^{17}$ se reemplazó íntegramente el procedimiento de aprobación de operaciones con partes relacionadas en sociedades anónimas abiertas y cerradas, ${ }^{18}$ y se estableció el requisito de contar con directores independientes y comité de directores para ciertas sociedades anónimas abiertas. ${ }^{19}$

Las modificaciones introducidas en la legislación nacional, si bien contribuyeron a mejorar el posicionamiento del país en mediciones internacionales sobre condiciones para hacer negocios, no fueron acompañadas por el desarrollo de un acervo jurisprudencial sobre conflictos societarios ni una experiencia institucional en la resolución de diferencias que involucran a socios y administradores de una sociedad.

Según la ley chilena, la resolución de conflictos societarios se hace por vía de arbitraje o, excepcionalmente, de la justicia ordinaria. Existen ciertas materias para las cuales la ley impone la resolución por la vía de un tribunal arbitral (materias de "arbitraje forzoso"), dentro de las cuales destaca la resolución de conflictos entre los accionistas de una sociedad anónima o de una sociedad por acciones en su calidad de tales y entre los accionistas y los administradores sociales. ${ }^{20}$ Sin perjuicio de lo anterior, en el caso de las sociedades anónimas, el demandante (salvo excepciones) es libre para sustraer el conocimiento del conflicto de la competencia de los árbitros y someterlo a la decisión de la justicia ordinaria, por lo que, en la práctica, el arbitraje sólo es obligatorio para el demandado. ${ }^{21}$

\section{${ }^{17}$ Ibídem.}

18 Ver Ley 20.382, del 20 de octubre de 2009, "Introduce perfeccionamientos a la normativa que regula los gobiernos corporativos de las empresas", República de Chile.

${ }^{19}$ Ibídem.

${ }^{20}$ De conformidad a lo dispuesto en el artículo 227 del Código Orgánico de Tribunales, son materias de arbitraje forzoso, entre otras, la liquidación de una sociedad colectiva o en comandita civil, las cuestiones a que diere lugar la presentación de la cuenta del gerente o del liquidador de las sociedades comerciales, y las diferencias que ocurrieren entre los socios de una sociedad anónima o (salvo disposición estatutaria en contrario) de una sociedad colectiva o en comandita comercial. Adicionalmente, el artículo 441 del Código de Comercio dispone, respecto de las sociedades por acciones, que las diferencias que ocurran entre los accionistas, entre los accionistas y la sociedad o sus administradores, y entre la sociedad y sus administradores, deberán resolverse por medio de arbitraje.

${ }^{21}$ Ver artículo 125 de la Ley 18.046 de 1981. 
Desde una perspectiva institucional, tanto en el caso de resolución de conflictos societarios por un tribunal arbitral como por la justicia ordinaria, el mecanismo de resolución de controversias dispuesto por el legislador resulta problemático. En el caso de la resolución de conflictos por vía de un tribunal arbitral, las partes deben incurrir no sólo en las costas naturales de los procesos judiciales (honorarios de abogados, notificaciones, comparecencias, etcétera), sino que además en remunerar a el o los jueces árbitro. ${ }^{22}$ Además, la resolución por jueces privados y confidencialidad habitual de estos procesos obsta a la creación de una jurisprudencia consistente y pública sobre las materias sometidas a su conocimiento, lo que dificulta crear un "historial" de los criterios utilizados por cada órgano jurisdiccional. ${ }^{23}$ La falta de sistematización y publicidad respecto de los criterios utilizados en la resolución de conflictos societarios por tribunales arbitrales afecta no sólo a potenciales litigantes, sino también a asesores legales, asesores contables, administradores societarios, jueces, autoridades, y a los agentes económicos en general.

La resolución excepcional por vía de la justicia ordinaria tampoco presenta un marco apto para el mejor desarrollo del derecho societario. Como se ha indicado, nuestro marco jurídico favorece el arbitraje como mecanismo de resolución de controversias societarias y, en general, las partes enfrentadas a tales controversias (en la medida de sus posibilidades) preferirán dicho mecanismo. La falta de disposición a recurrir a los tribunales ordinarios (considerando que hay casos en que la ley de-

${ }^{22}$ En la página web del Centro de Arbitraje y Mediación de la Cámara de Comercio de Santiago se encuentran disponibles los honorarios arbitrales y tasas administrativas cobradas para juicios arbitrales conducidos por árbitros de dicho centro. A modo ilustrativo, los honorarios arbitrales para un litigio con importe entre las 8.001 y 25.000 UF pueden llegar hasta el 4 por ciento del importe correspondiente, a lo que debe sumarse una tasa administrativa equivalente al 10 por ciento de los honorarios del tribunal arbitral. Ver http://www.camsantiago.cl/tarifas/nacional.html (accedido el 16 de enero de 2019).

${ }^{23}$ A modo ilustrativo, los documentos relativos a arbitrajes tramitados ante jueces árbitro del Centro de Arbitraje y Mediación de la Cámara de Comercio de Santiago sólo son accesibles para las partes, sus abogados y los funcionarios de dicho Centro. Actualmente, tal Centro sólo pone a disposición del público ciertas sentencias seleccionadas, por medio de libros y CDs producidos periódicamente que están a la venta (según información proporcionada por la oficina de estudios del Centro, se ha descontinuado la práctica de poner algunas sentencias seleccionadas gratuitamente a disposición del público en su página web). 
rechamente no lo permite $)^{24}$ es atribuible, presumiblemente, a una baja exposición de los mismos a este tipo de controversias (lo que es posible consecuencia, a su vez, del desfavorecimiento por el legislador), la mayor especialización ofrecida por los tribunales arbitrales y el tiempo que tarda obtener un fallo ejecutoriado. Esto dificulta el desarrollo de experiencia por parte de la justicia ordinaria en dirimir disputas societarias. Además, la tradición del sistema jurídico chileno, de marcada raíz europea continental, pone trabas significativas a la resolución expedita de conflictos de índole comercial. De manera creciente, el mundo de los negocios requiere celeridad, la que entra en conflicto con las intrincadas reglas de procedimiento y el abanico de recursos procesales que caracterizan los procesos sometidos a la justicia ordinaria. Muchas veces, incluso, las discusiones sobre las reglas del procedimiento se imponen en desmedro del asunto sustantivo. Esta hiperdependencia en las reglas procedimentales permea también la enseñanza impartida en las escuelas de derecho del país y de tal manera se contribuye a su enraizamiento y perpetuación..$^{25,26}$

La escasa exposición que han tenido los tribunales ordinarios, en sus distintos niveles, a conflictos societarios puede inferirse de los gráficos 1, 2 y 3 . Estos comparan, para el período de cinco años com-

${ }^{24}$ Según el artículo 125 de la Ley sobre Sociedades Anónimas, no pueden recurrir a la justicia ordinaria los demandantes que sean directores, gerentes, administradores, ejecutivos principales y accionistas que individualmente posean, directa o indirectamente, acciones cuyo valor libro o bursátil supere las 5.000 UF, de acuerdo con el valor de dicha unidad a la fecha de presentación de la demanda. Adicionalmente, de conformidad al artículo 441 del Código de Comercio, la ley no permite recurrir a la justicia ordinaria para la resolución de disputas originadas en las sociedades por acciones.

${ }^{25}$ En conferencia en la Superintendencia de Sociedades de Colombia el 13 de julio de 2017, el profesor José Miguel Mendoza destacó que, mientras que en Harvard existe un solo ramo semestral obligatorio de derecho procesal y en Oxford tales ramos obligatorios no existen, universidades en Colombia — país de tradición jurídica similar a la de Chile - exigen hasta ocho ramos obligatorios en la materia (ponencia disponible en https://livestream.com/supersociedades/events/7598890/videos/159752976). En Chile, tanto la Facultad de Derecho de la Pontificia Universidad Católica de Chile como de la Universidad de Chile, a modo ejemplar, incluyen cinco cursos semestrales mínimos de derecho procesal en su malla curricular.

${ }^{26}$ Ver Aurelio Gurrea Martínez, "La sociedad por acciones simplificada como paradigma de innovación jurídica: una reflexión sobre la función social de los investigadores de derecho a partir de la experiencia de la SAS en Colombia", Instituto Iberoamericano de Derecho y Finanzas Working Paper Series 2/2018 (2018), 8-9. Disponible en http://dx.doi.org/10.2139/ssrn.3097775. 
Gráfico 1. FALLOS QUE CITAN LA LEY SOBRE SOCIEDADES ANÓNIMAS (LSA) Y FALLOS TOTALES EN MATERIA CIVIL DICTADOS POR JUZGADOS CIVILES (2013-2017)

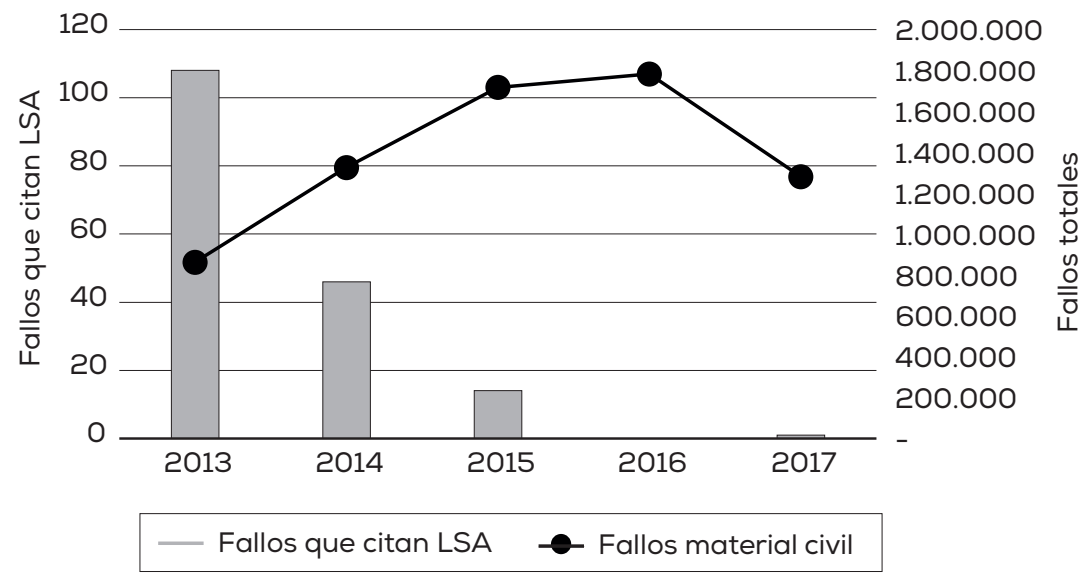

Fuente: Elaboración propia en base a información obtenida de Poder Judicial de Chile, Memorias Anuales 2013-2017 (http://www.pjud.cl/memorias-anuales), documento "Poder judicial en números 2018. Estadistica de causas. Tomo I", agosto de 2018 (http:// www.pjud.cl/documents/10179/11855875/1.Estadisticas+de+Causas.pdf/6c10b2044f22-4b13-975c-8416f8eaObe7?version=1.2), y buscador jurisprudencial de suscripción, en búsqueda efectuada el 21 de noviembre de 2018 .

Gráfico 2. FALLOS QUE CITAN LA LEY SOBRE SOCIEDADES ANÓNIMAS (LSA) Y FALLOS TOTALES EN MATERIA CIVIL DICTADOS POR CORTES DE APELACIONES (2013-2017)

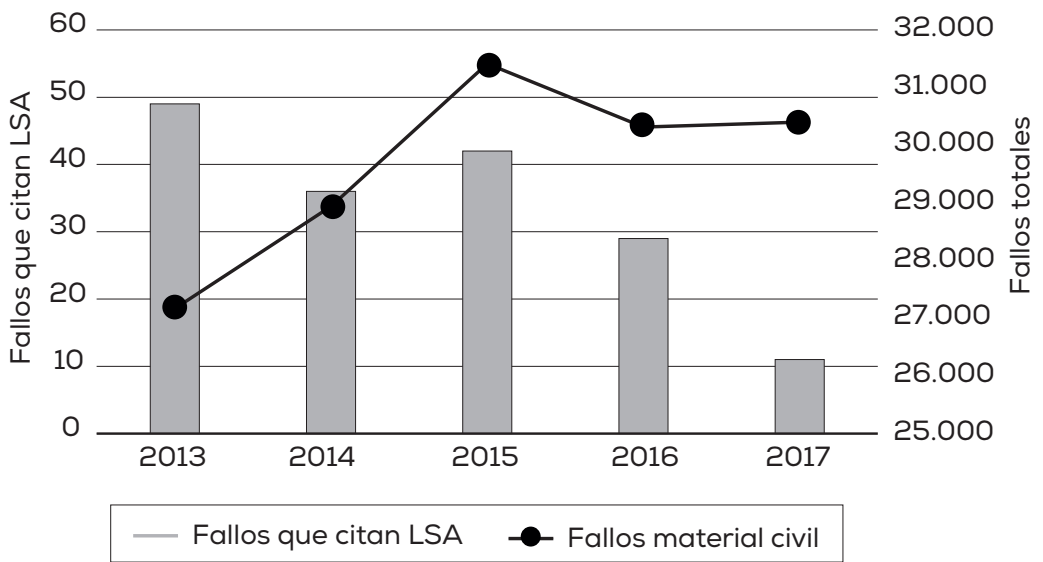

Fuente: Ibidem gráfico 1. 
Gráfico 3. FALLOS QUE CITAN LA LEY SOBRE SOCIEDADES ANÓNIMAS (LSA) Y FALLOS TOTALES EN MATERIA CIVIL DICTADOS POR LA CORTE SUPREMA (20132017)

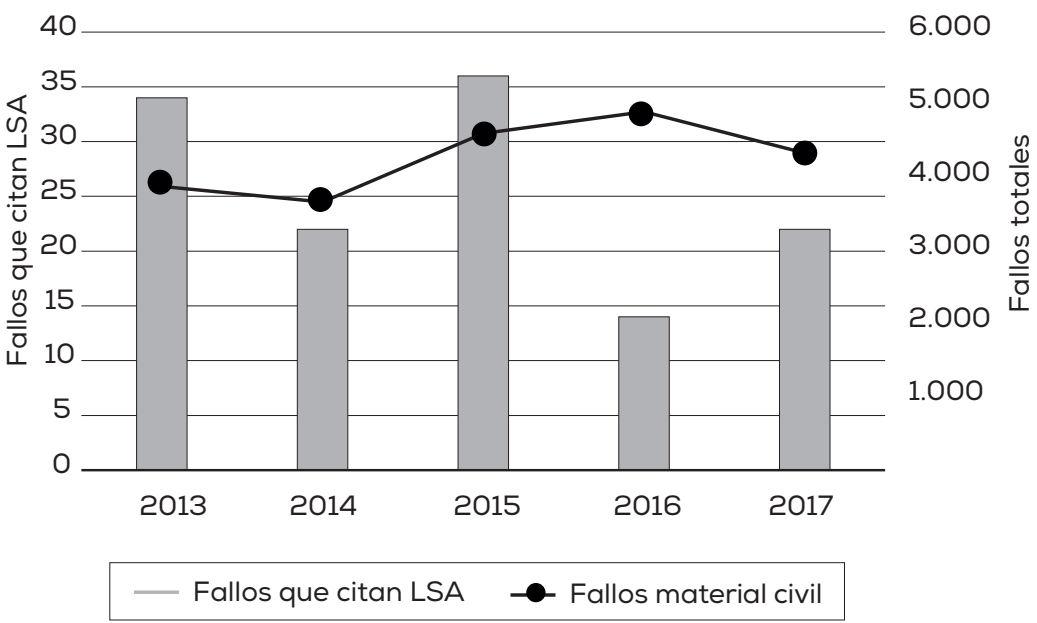

Fuente: Ibídem gráfico 1.

prendido entre los años 2013 y 2017, los fallos (entendiendo por tales sentencias definitivas) que citan la Ley sobre Sociedades Anónimas con el total de fallos en materia civil dictados por los tribunales ordinarios para cada año del período. ${ }^{27}$ En cualquier caso, debe tenerse presente que esta evidencia es meramente referencial, dado que el contrafactual - disputas que las partes se abstienen de someter a la resolución de la justicia ordinaria - no puede conocerse.

En el gráfico 4 se expone la razón de fallos de los tribunales ordinarios que citan la Ley sobre Sociedades Anónimas sobre los fallos totales en materia civil de los tribunales ordinarios para cada año del período 2013-2017.

Considerando el total de fallos para el período 2013-2017, la razón de fallos de los tribunales ordinarios que citan la Ley sobre Sociedades Anónimas por sobre el total de fallos en materia civil de los tribunales

${ }^{27}$ Debe considerarse que la estadística está elaborada en base a sentencias definitivas que meramente citan la Ley Sobre Sociedades Anónimas, lo que en ningún caso quiere decir que un conflicto societario haya sido necesariamente medular en la resolución del litigio. 
Gráfico 4. RAZÓN DE FALLOS QUE CITAN LA LEY SOBRE SOCIEDADES ANÓNIMAS SOBRE EL TOTAL DE FALLOS EN MATERIA CIVIL DICTADOS POR LOS TRIBUNALES ORDINARIOS (2013-2017)

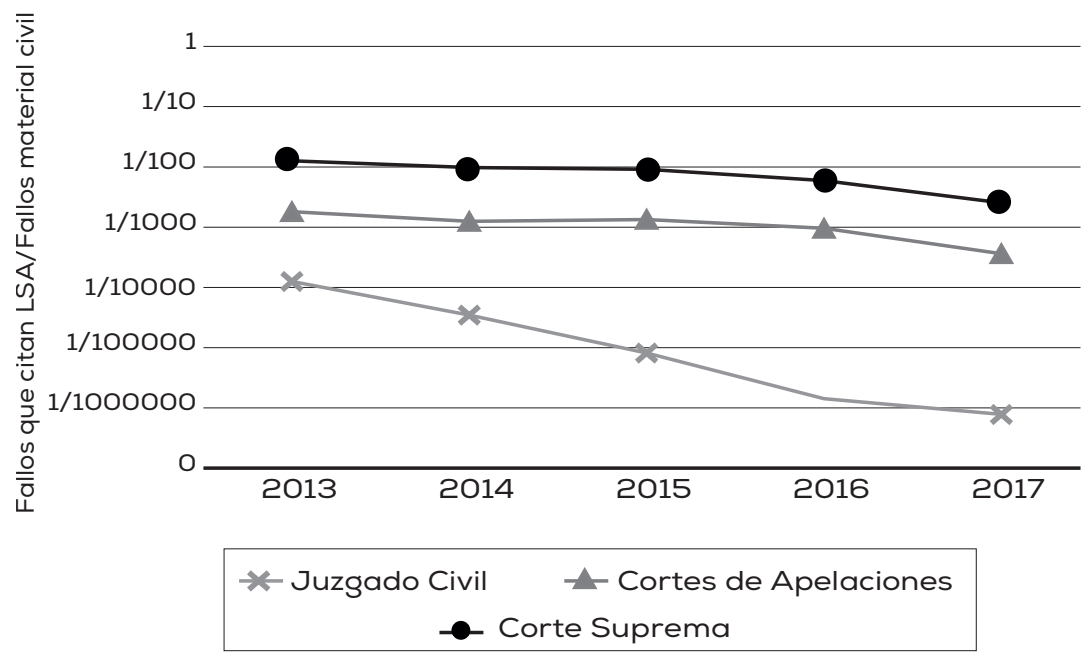

Fuente: Ibidem gráfico 1.

ordinarios, así como el promedio anual de fallos de los tribunales ordinarios que citan la Ley sobre Sociedades Anónimas, es el siguiente:

\begin{tabular}{lcc}
\hline Tribunal & $\begin{array}{c}\text { Fallos que citan Ley sobre } \\
\text { Sociedades Anónimas / } \\
\text { Fallos materia civil }\end{array}$ & $\begin{array}{c}\text { Promedio anual de fallos } \\
\text { que citan Ley sobre } \\
\text { Sociedades Anónimas }\end{array}$ \\
\hline Juzgados civiles & $1 / 41.243$ & 34 \\
Cortes de Apelaciones & $1 / 888$ & 33 \\
Corte Suprema & $1 / 167$ & 26 \\
\hline
\end{tabular}

Un análisis pormenorizado de las sentencias dictadas por los tribunales ordinarios en el mismo período es consistente con los hallazgos de bajos niveles de litigiosidad antes expuestos. Utilizando como referencia sentencias dictadas entre los años 2013 y 2017 en las cuales un aspecto sustantivo de las mismas haya requerido un análisis o revisión de los artículos 30 (deber de los accionistas de ejercer sus derechos sociales respetando los de la sociedad y los de los demás accionistas), 44 (operaciones con partes relacionadas en las sociedades anónimas 
cerradas) o 133 bis (acción en virtud de la cual uno o más accionistas se subrogan en la posición de la compañía para exigir la reparación de los ilícitos cometidos por sus directores, gerentes u otros en perjuicio de la misma) de la Ley sobre Sociedades Anónimas, se observan tan sólo tres fallos referidos al primero (todos en Cortes de Apelaciones), ${ }^{28}$ cuatro fallos referidos al segundo (uno en juzgados civiles, uno en Cortes de Apelaciones y dos en Corte Suprema), ${ }^{29}$ y un fallo referido al tercero (en Corte Suprema). ${ }^{30}$ Debe tenerse presente que todas estas disposiciones son medulares en el marco regulatorio nacional para la protección de accionistas minoritarios.

En términos de plazos, a modo de referencia, para el periodo 20132017 el promedio de duración de causas civiles sujetas a procedimiento ordinario terminadas con sentencia definitiva de primera instancia fue de 534 días. Para el periodo 2014-2017, el promedio de duración de causas en la Sala Civil de la Corte Suprema fue de 103 días (el valor para procedimientos ante Cortes de Apelaciones no está disponible, al igual que para Corte Suprema el año 2013). ${ }^{31}$ En cuanto a los procedimientos judiciales que han incluido un análisis o revisión de los artículos 44 o 133 bis de la Ley sobre Sociedades Anónimas y que han obtenido sentencia

${ }^{28}$ Búsqueda efectuada en buscador jurisprudencial de suscripción los días 7 , 8, y 10 de enero de 2019. Causas rol 5707/2015 Res. 1012404, de 5 de noviembre de 2015 (Corte de Apelaciones de Santiago); 5708/2015 Res. 1012393, de 5 de noviembre de 2015 (Corte de Apelaciones de Santiago); y 4213/2014 Res. 1366714, de 26 de diciembre de 2014 (Corte de Apelaciones de Santiago). En todas las anteriores, la consideración al artículo 30 de la Ley sobre Sociedades Anónimas se ha hecho en relación con el derecho de información que asiste a los accionistas.

29 Búsqueda efectuada en buscador jurisprudencial de suscripción los días 7, 8, y 10 de enero de 2019. Causas 3329/2015 Res. 162874, de 21 de marzo de 2016 y 9303/2012 Res. 238597, de 29 de octubre de 2014 (ambas de la Corte Suprema); 13384-2012, de 4 de diciembre de 2013 (30 Juzgado Civil de Santiago) y 1440/2011 Res. 20960, de 17 de enero de 2013 (Corte de Apelaciones de Santiago). Una discusión interesante sobre el deber de lealtad que recae sobre los directores de sociedades anónimas y uso de información privilegiada se encuentra en opinión disidente de causa rol 205/2012 Res. 60362 de 28 de agosto de 2013 (Corte Suprema).

30 Búsqueda efectuada en buscador jurisprudencial de suscripción los días 7 , 8 y 10 de enero de 2019. Causa rol 9303/2012 Res. 238597, de 29 de octubre de 2014. Nótese que esta sentencia también ha incluido un análisis del artículo 44 de la Ley sobre Sociedades Anónimas, según se ha indicado previamente.

${ }^{31}$ Poder Judicial de Chile, "Poder judicial en números. Tomo I. Estadísticas de causas". (para años 2015 al 2018). Disponible en http://www.pjud.cl/poder-judicialen-numeros. 
de la Corte Suprema, la duración de los mismos fue de nueve años y tres meses, en un caso, y de seis años y ocho meses, en el otro.

Así, por una parte, las reglas escritas satisfacen, en general, buena parte de los criterios dictados por los organismos internacionales para la adecuada protección de inversionistas de capital. Sin embargo, ya sea por los costos involucrados, la carencia de incentivos, la falta de experiencia o los tiempos requeridos, en la realidad ha sido poca la experiencia institucional desarrollada en la resolución de conflictos societarios. La judicialización excepcionalísima de conflictos societarios que revela la muestra anterior hace irrealista pretender que el marco actual conducirá al desarrollo de una experiencia institucional en el entendimiento y resolución de dichos conflictos (al menos en lo referido a los tribunales ordinarios). De manera semejante, los plazos requeridos para obtener una sentencia ejecutoriada (que no admita recurso alguno) son del todo incompatibles con el curso regular de las relaciones de negocios actuales, haciendo ilusoria la efectividad de la certeza jurídica pretendida por las partes. Estas carencias repercuten en los oferentes de capital, los que difícilmente confiarán en que las reglas escritas garantizarán en toda circunstancia su tratamiento justo y demandarán más por sus aportes. Si bien las condiciones ofrecidas por los tribunales arbitrales pueden ser más favorables, en términos de experiencia de los juzgadores y tiempos de resolución, como se ha indicado previamente, sus servicios no son gratuitos - generando barreras a su acceso - y su jurisprudencia no es pública - limitando el desarrollo de experiencia institucional y criterios formadores en la resolución de conflictos societarios-.

La implementación de un sistema de control ex ante, si bien es apta para jurisdicciones en las que existen altos riesgos de tunneling y falta de experiencia institucional en la resolución de disputas societarias, presenta también considerables inconvenientes. En primer lugar, la determinación de parámetros con anterioridad a la consumación de las conductas puede obstar o imponer trabas (incluyendo altos costos) a la realización de actuaciones que no sólo pueden ser legítimas, sino que además convenientes para la sociedad y los accionistas minoritarios. ${ }^{32}$

32 Considerar, por ejemplo, el caso de préstamos otorgados en condiciones de mercado a entidades relacionadas nuevas o con propósitos especiales (como organizaciones sin fines de lucro) que no podrían acceder a financiamiento externo o, si lo hicieran, tendrían que asumir condiciones más gravosas. Bajo el actual 
En segundo lugar, si bien el grueso de la intervención estatal se requiere al tiempo del diseño de las normas, una política pública responsable requiere incurrir en altos costos para asegurar — de manera continuaque las mismas se adecúen a las prácticas comerciales imperantes. ${ }^{33}$ La falta de revisión continua se traducirá, necesariamente, en la obsolescencia e ineficacia de los propósitos inicialmente previstos para la regulación. En tercer lugar, la inmutabilidad de la norma escrita facilita el desarrollo de estrategias para su evasión desde el momento mismo en que entra en funcionamiento. Así, las partes interesadas tendrán incentivos para generar condiciones mediante las cuales puedan expropiar a los minoritarios de una manera que no se encuentre expresamente prevista por la norma, con bajos riesgos de escrutinio debido a la falta de judicialización. Finalmente, la reglamentación previa a las conductas conduce a falta de litigación, impide el desarrollo de experiencia en la resolución de conflictos societarios, eventualmente genera desconfianza en las instituciones judiciales para resolver dichos conflictos y obliga a las partes a incurrir en altos costos para zanjar las disputas que - de todas formas - se van a suscitar. Esta aversión a zanjar judicialmente las contiendas genera brechas en la experiencia judicial necesaria para brindar certezas jurídicas a las partes, de la misma manera que la falta de experiencia de las cortes produce aversión a demandar. Tal círculo

sistema de control ex ante, estos préstamos debieran sujetarse a los procedimientos de aprobación contemplados en el artículo 44 o el Título XVI de la Ley sobre Sociedades Anónimas, según si la sociedad anónima es cerrada o abierta. Si bien es cierto que la entidad relacionada que sería acreedora podría también ofrecer una garantía a favor de una institución financiera para que otorgue el préstamo, nada asegura que ello sea suficiente para ésta última. Otro ejemplo es el caso en que la ley fuerza la distribución de un porcentaje de las utilidades sociales (30 por ciento) en las sociedades anónimas abiertas y, supletoriamente, en las sociedades anónimas cerradas (artículo 79 de la Ley sobre Sociedades Anónimas), lo que podría dificultar el desarrollo de proyectos de innovación y la reinversión de utilidades (nótese que la excepción a dicha distribución forzosa requiere unanimidad de los accionistas).

${ }^{33}$ Por ejemplo, la regulación de la oferta pública de adquisición de acciones en Chile vio la luz por el llamado "Caso Chispas", de fines de los años noventa. En dicho caso, según se argumentó, los controladores de facto de una sociedad nacional negociaron condiciones de venta más favorables para sí que para los demás accionistas. Más recientemente, el llamado "Caso Cascadas" encendió las alarmas sobre los desafíos que presentan a los reguladores y el mercado esquemas piramidales o de cascada, los que desvirtúan el principio que impide separar la propiedad del control o "una acción, un voto". 
vicioso no sólo es perjudicial para el adecuado remedio de la vulneración de las reglas en vigor, sino también para resolver la innumerable cantidad de controversias que pueden suscitarse en el ámbito de las interacciones societarias y que, como es natural, no están previstas en la ley.

\section{LA TRANSICIÓN DE REGLAS A ESTÁNDARES}

Cualquiera sea el sistema que se adopte, el desafío sigue siendo el mismo: interpretar actos complejos para, con independencia de sus formas, detectar la expropiación de accionistas mayoritarios en perjuicio de los minoritarios. El objetivo es, entonces, apuntar a un sistema que favorezca que los costos que sufren los minoritarios por expropiación de los mayoritarios no sobrepasen los beneficios emanados de la presencia de un socio controlador (en la forma de monitoreo de los administradores, apoyo de sociedades relacionadas y conocimiento del negocio, entre otros). Debe también considerarse que es eficiente que el controlador reciba alguna compensación razonable por sus esfuerzos en el monitoreo de los administradores y en la creación e implementación de proyectos, así como por el riesgo específico que asume en la empresa (y la diversificación que sacrifica) en comparación a los demás accionistas. ${ }^{34}$ En definitiva, se requiere de un sistema que permita a los controladores comprometerse a extraer un nivel razonable y creíble de beneficios privados del control, de manera tal que se limiten los problemas de selección adversa en el financiamiento de capital y se favorezcan estructuras de control eficientes; que maximicen los beneficios para la sociedad derivados de la presencia de accionistas controladores. ${ }^{35}$

Como consecuencia de la globalización, las nuevas tecnologías y la internacionalización de las prácticas comerciales, las relaciones comerciales se desenvuelven en contextos cada vez más complejos. Es así como el derecho debe ponerse al servicio de la forma actual en que se hacen los negocios, y no al revés. Una transición desde un marco jurídico basado en reglas (pilares de un sistema de control ex ante) hacia uno

\footnotetext{
${ }^{34}$ Gilson y Schwartz, "Constraints on Private", 4.

${ }^{35}$ Ibídem, 37.
} 
basado en estándares (pilares de un sistema de control ex post) favorecería estos propósitos.

La adopción exitosa de un sistema de derecho societario que incorpore estándares tendría beneficios importantes para el país. En primer lugar, permitiría revitalizar el derecho societario como una herramienta de política económica, de forma que contribuya a la promoción del comercio por vía de proveer un mecanismo confiable y gratuito para la resolución de disputas en el contexto societario. Esto requiere, por cierto, liberar la carga de intrincados formalismos procesales (por ejemplo, en lo relacionado con notificaciones, presentaciones, excepciones, pruebas y recursos), los que entorpecen tanto el mejor desarrollo de las iniciativas de negocios como la adecuada resolución de conflictos de naturaleza eminentemente comercial (más que jurídica).

En segundo lugar, en un mundo de inversionistas globales, fondos de inversión ávidos de certezas y férrea competencia regional por la atracción de capitales, avanzar en esta dirección beneficiaría tanto a quienes se asocian regularmente por razones de negocios, como también a las nuevas mentes creativas locales que busquen capital dentro y fuera de Chile para el desarrollo y escalamiento de sus ideas. Desarrollar una reputación regional como expertos en derecho societario ciertamente favorecería la llegada de capitales al país, disminuyendo los costos del financiamiento empresarial.

En tercer lugar, la adopción de un sistema de control ex post permitiría hacer frente a una realidad que sólo cabe reconocer (ya no resistir, si fue alguna vez el caso): nuestros contratos comerciales (incluyendo contratos de compraventa de acciones y pactos de accionistas), de manera incremental, se han ido repletando de conceptos anglosajones. ${ }^{36}$ Basta ver lo recurrente que son términos como tag along, drag along, right of first refusal, call y put option, covenants y representations \& warranties (con sus correspondientes traducciones al español). La adecuada aplicación de estos conceptos — emanados de la práctica comercial, y no de la normativa jurídica - requiere de conocimientos específicos sobre sus propósitos y funcionamiento, así como de un adecuado entendimiento de los hechos concretos que son materia de disputa.

${ }^{36}$ Para una discusión sobre la integración de estos términos en la legislación comercial chilena, ver Jorge Ugarte Vial, Pactos sobre transferencia de acciones (Santiago: Editorial Jurídica de Chile, 2016), 333-369. 
Tales conocimientos y entendimiento sólo pueden ser aplicados en una revisión con posterioridad a la actuación (u omisión) controvertida y requieren considerable experiencia institucional, la que únicamente puede desarrollarse conociendo problemas del mundo real.

Finalmente, un involucramiento más activo de los tribunales de justicia ayudaría a desarrollar experiencia en la resolución de disputas societarias y generaría un acervo jurisprudencial que otorgue guías de conducta e influencie, de manera dinámica y sensible a la realidad, el comportamiento futuro de los actores económicos (en la forma en que la autoridad experta así lo determine). Todas estas consecuencias positivas, sumadas a la reconocida estabilidad política y económica del país, podrían contribuir al posicionamiento y consolidación de Chile como un centro financiero líder en Latinoamérica.

La transición hacia los estándares planteada y las propuestas discutidas a continuación bien podrían implementarse para sociedades de mayor tamaño, entendiendo por tales aquéllas que coticen sus acciones en las bolsas de valores de Chile. Sin embargo, debido a la complejidad y experiencia requerida para hacerlo de manera exitosa en dichas sociedades, una implementación gradual, comenzando por sociedades que no hagan oferta pública de sus acciones, es posiblemente el camino más aconsejable para iniciar la transición.

\section{HACIA UNA NUEVA INSTITUCIONALIDAD}

La mayor estabilidad política del país, junto a la experiencia desarrollada en la implementación de foros especializados en la resolución de conflictos para algunas materias, representan un cambio de circunstancias respecto a aquellas que en las décadas de los ochenta y dos mil llevaron a establecer, y luego reforzar, un sistema basado en prohibiciones y reglas de autocumplimiento. Tal cambio de circunstancias, apoyado por las virtudes de los propósitos perseguidos con el nuevo modelo, así como un buen precedente en la región, ameritan la consideración de cómo podría llevarse adelante una transición hacia un sistema que paulatinamente privilegie los estándares. Dicha transición no limita la consolidación de un sistema mixto, que conserve prohibiciones y reglas de autocumplimiento estimadas valiosas. Pero el desarrollo de un sistema tal no está exento de desafíos. Para que el camino sea exitoso se requiere sortear obstáculos difíciles, tanto por las tradiciones enraizadas 
en la comunidad jurídica nacional como por los recursos humanos y materiales requeridos. Una evolución lograda requiere, al menos, de cuatro pilares: estándares adecuados, tribunales especializados, reglas procesales que privilegien la eficacia y la eficiencia, y políticas públicas que otorguen los incentivos correctos.

\subsection{Estándares}

En primer lugar, se requiere la implementación de estándares adecuados. En un mundo donde las prácticas comerciales son dinámicas, las normas padecen riesgos permanentes de obsolescencia. Es así como la estabilidad, de manera creciente, se encuentra en la adaptabilidad más que en la rigidez. Se requiere, entonces, de estándares que permitan recoger las conductas comerciales imperantes, incorporen criterios de equidad y se muevan en la tenue línea que separa la concreción y la generalidad. Ellos deben ser lo suficientemente concretos para delimitar razonablemente la conducta esperable y orientar las decisiones del proceso de revisión, y lo suficientemente flexibles para permitir su aplicación a las circunstancias particulares y su evolución según los tiempos y prácticas así lo requieran. Además, los estándares son herramientas de política pública y, como tales, deben diseñarse de una forma tal que promuevan eficiencias (reduciendo prohibiciones y permitiendo niveles razonables y creíbles de beneficios privados del control) y eliminen barreras al libre comercio.

Algunos ejemplos de estándares implementados en forma exitosa en otros países (incluyendo con origen jurisprudencial) son la regla de la discrecionalidad, o business judgment rule, que permite abstenerse de revisar judicialmente decisiones de negocios, a menos que exista conflicto de interés; ${ }^{37}$ el levantamiento del velo societario, que permite prescindir de la forma societaria y alcanzar a los socios, en caso de abuso de dicha forma; y recursos contra el ejercicio abusivo de pre-

${ }^{37}$ Esta regla puede ser particularmente útil en contextos como el latinoamericano, dado que, al predominar los vehículos de negocios con un socio controlador, los administradores se encuentran adecuadamente monitoreados. Así, las actuaciones cuestionables se generarán más por conflictos de interés (infracciones al deber de lealtad) que por falta de diligencia en la administración del negocio (infracciones al deber de cuidado). 
rrogativas sociales, por ejemplo, abuso del derecho a voto o actos de los accionistas mayoritarios mediante los cuales éstos desvían recursos sociales para su propio beneficio en desmedro de la sociedad y los intereses de los minoritarios. Si bien es cierto que algunos de estos estándares y conceptos han sido recogidos de cierta forma por la legislación, la jurisprudencia o la doctrina nacional, la falta de litigios relacionados y de puesta en práctica de tales estándares y conceptos obsta a su plena vigencia, aplicación y desarrollo. Así, por ejemplo, la Ley sobre Sociedades Anónimas - de manera sumamente escueta - reconoce un deber de los accionistas de ejercer sus derechos sociales respetando los de la sociedad y los de los demás accionistas (establecido en el artículo 30 de dicho cuerpo legal); pero, como se ha visto, esta disposición ha tenido un muy escaso (y casi inexistente) desarrollo jurisprudencial. En cuanto a la regla de la discrecionalidad y el levantamiento del velo societario, no hay norma legal alguna.

A nivel local, sería deseable también el desarrollo jurisprudencial de estándares que hoy consagra la legislación societaria chilena, pero que, por su falta de elaboración, son prácticamente inoperantes. Un ejemplo es el deber de los accionistas de respetar los derechos de terceros, según establece el ya citado artículo 30 de la Ley sobre Sociedades Anónimas. Otro caso es el concepto de "interés social", elemento referido en diversas disposiciones de la Ley sobre Sociedades Anónimas y medular para resolver una pluralidad de asuntos propios de la marcha societaria, incluyendo algunos tan relevantes como los conflictos de interés entre quienes tienen injerencia en la administración de la sociedad y esta última. ${ }^{38}$ Estándares como los anteriores deben ser complementados con principios generales del derecho civil, como la autonomía de la voluntad, la buena fe contractual y la libre circulación de los bienes, los que podrían consagrarse por la vía de estándares en la regulación societaria y ser aplicados en ese contexto por jueces expertos.

${ }^{38}$ Ver, por ejemplo, los artículos 6 y 6A (responsabilidad ante terceros de sociedad nula o constituida defectuosamente), 42 (prohibiciones a los directores), 43 (deber de reserva de los directores), 54 (reserva sobre negociaciones pendientes antes de una junta ordinaria de accionistas) y 147 (operaciones con partes relacionadas en las sociedades anónimas abiertas) de la Ley sobre Sociedades Anónimas. 


\subsection{Tribunales especializados}

En segundo lugar, se requiere de cortes especializadas en materias societarias. Chile ha desarrollado experiencia en la implementación de tribunales especiales en el ámbito tributario y aduanero, de propiedad industrial, de libre competencia, ambiental y de contratación pública; todos tribunales que, sin ser parte de la estructura administrativa del Poder Judicial, están sujetos a su supervigilancia directiva, correccional y económica, ejercida a través de la Corte Suprema. ${ }^{39}$ La figura de un tribunal especial con facultades para resolver las más amplias controversias en materias societarias, tanto en lo referido a disposiciones legales y reglamentarias como derivadas de acuerdos entre socios, permitiría dar el paso adelante que se requiere para desarrollar una experiencia institucional en la resolución de tales controversias. En efecto, se requiere de un salto cualitativo para dar respuestas a la situación actual, caracterizada por riesgo de abusos como consecuencia de la alta concentración que existe en el control de sociedades, poca experiencia en la resolución de disputas societarias, y excesivas reglas procesales. Foros especializados de este tipo han sido establecidos en Holanda, ${ }^{40}$ Israel $^{41}$ y Colombia. A ellos debe sumarse la Corte Estatal de Delaware,

${ }^{39}$ A ellos deben sumarse los tribunales especiales que forman parte del Poder Judicial, como los Juzgados de Familia, Juzgados de Letras del Trabajo y Juzgados de Cobranza Laboral y Previsional.

${ }^{40}$ Para advertir el potencial de tribunales especializados en materias societarias (incluso como foro internacional), basta revisar la página web desarrollada por una oficina de abogados local para promocionar la nueva corte holandesa para la resolución de disputas comerciales (The Netherlands Commercial Court). Este nuevo tribunal - cuyos procedimientos se desarrollarán en inglés- es promocionado como una alternativa a foros más costosos para la resolución de conflictos societarios, como Londres o Estados Unidos, y para aquellas partes que no quieren someter sus controversias a arbitraje, en el que "los procedimientos son costosos y los resultados pueden no ser tan predecibles como ante cortes nacionales" ("A First Guide to Commercial Litigation in the Netherlands", Blenheim, accedido el 26 de noviembre de 2018, https://netherlands-commercial-court.com/\#).

${ }^{41}$ Un estudio por Yifat Aran, de Stanford University, concluye que la experiencia de Israel, mediante una división especializada para asuntos societarios en la Corte de Distrito de Tel Aviv (creada en 2010), ha sido exitosa. Analizando 242 acciones de clase y derivativas sometidas tanto a la división especializada como a las cortes distritales generales entre 2006 y 2014, destaca que la "especialización ha probado ser un medio efectivo para potenciar el poder judicial y promover la protección de los inversionistas", observando efectos positivos en eficiencia, generación de precedentes y trabajo de unificación jurisprudencial (Yifat Aran, "From Delaware to Israel: Evaluating Israel's Quasi Experiment of a Specialized Corporate Court", disponible en SSRN (2015), http://dx.doi.org/10.2139/ssrn.2619916). 
en Estados Unidos, que, si bien no tiene el carácter de tribunal especial para asuntos societarios, en la práctica, por la jurisprudencia desarrollada a lo largo de los años y la experiencia de sus jueces, es un tribunal reconocido internacionalmente como experto en estos asuntos. ${ }^{42}$ Estos tribunales especiales a ser implementados en Chile difieren sustancialmente de los tribunales arbitrales actualmente existentes (foros también especializados) en tres aspectos fundamentales. Primero, los tribunales especializados propuestos promoverían de mejor manera el acceso a la justicia, al ser gratuitos. Segundo, facilitarían la unificación, desarrollo y evolución de criterios, al ser públicas todas sus actuaciones y resoluciones. Finalmente, contribuirían al mejor control de la calidad de las decisiones, al permitir procesos competitivos, objetivos y transparentes en la designación de sus miembros, así como en la evaluación de su desempeño.

El establecimiento de cortes especializadas a lo largo del país, como es natural, requiere de jueces con la independencia, habilidades y conocimientos adecuados para servir su cargo. Estos letrados deberían tener familiaridad con los fundamentos de las interacciones comerciales y ser capaces de privilegiar la eficacia y eficiencia en la resolución de conflictos, teniendo un rol más proactivo e inmediato que el característico de los procedimientos civiles. Asimismo, es de la mayor importancia que los juzgadores tengan formación multidisciplinaria, que incluya competencias en materia contable, financiera y el análisis económico del derecho. Particularmente respecto a este último, los jueces deben ser capaces de visualizar cómo las decisiones de un caso particular generan incentivos para comportamientos futuros, tanto por las partes del caso concreto, como también por todos los potenciales usuarios del tribunal. Por la naturaleza de las competencias y experiencia requerida, sería conveniente que las vacantes de los tribunales especializados se llenaran mediante concursos abiertos regidos por el Sistema de Alta Dirección Pública (como ocurre, por ejemplo, con los Tribunales Tributarios y Aduaneros y los Tribunales Ambientales), en los cuales se exija a

42 Como consecuencia de esto (junto con otras prerrogativas normativas), más de dos tercios de las compañías listadas en Fortune 500 están constituidas en Delaware, como también cuatro de cada cinco compañías que comienzan a hacer oferta pública de sus acciones en Estados Unidos ("A Message from the Secretary of State - Jeffrey W. Bullock", Delaware Division of Corporations, accedido el 19 de noviembre de 2018. Disponible en https://corp.delaware.gov/stats/). 
los postulantes el cumplimiento de ciertos requisitos de independencia, formación y experiencia. También sería deseable el involucramiento en el proceso de selección de los tribunales superiores de justicia y, según se sugerirá a continuación, en la Comisión para el Mercado Financiero.

Los tribunales societarios especializados, por sus características particulares $-\mathrm{y}$ sin perjuicio de poder optarse por otras alternativas, incluyendo una dependencia directa del Poder Judicial, sin que se desvirtúe el modelo de cuatro pilares propuesto-, podrían depender de la Comisión para el Mercado Financiero, mediante el otorgamiento de facultades jurisdiccionales especiales. Esto, al menos en una primera etapa, en que no estén sujetas a la jurisdicción de los nuevos tribunales entidades sometidas a la fiscalización de la mencionada entidad. De tal manera, una división de esta Comisión tendría a su cargo la implementación, gestión y administración del órgano jurisdiccional especializado, debiendo establecerse reglas adecuadas para salvaguardar la independencia de decisión y uso de recursos por parte del mismo. Esta alternativa - escogida por el precedente latinoamericano que existe en la materia, según se expone más adelante - parece especialmente conveniente, pues permitiría aprovechar la experiencia especializada que actualmente existe en el aparato público respecto a la interacción con sociedades comerciales. Si fuese conveniente, en una segunda etapa se podrían incluir en el nuevo sistema entidades reguladas y, con ello, plantearse la opción de que los tribunales societarios especializados se escindan del Poder Ejecutivo y pasen a integrar la lista de los tribunales especiales sujetos a la supervigilancia del Poder Judicial. Además, para garantizar la libertad de las partes, debería salvarse el derecho del demandante de someter las contiendas a arbitraje o bien a la justicia ordinaria, en forma equivalente a lo prescrito por el actual artículo 125 de la Ley sobre Sociedades Anónimas. Así, la sujeción de las partes al nuevo tribunal sería voluntaria. Pudiendo razonablemente preverse que partes financieras sofisticadas en contiendas que involucren montos mayores, al menos en principio, continuarán recurriendo a arbitrajes para la resolución de conflictos societarios; las nuevas cortes otorgarían una opción gratuita, expedita, y especialmente útil para todos los demás intervinientes en relaciones societarias, incluyendo emprendedores y socios de pequeñas y medianas empresas.

La propuesta de implementar tribunales especiales en materia societaria probablemente requeriría hacerse cargo de las críticas de 
quienes son contrarios a la atomización de la judicatura y de quienes creen que las reformas contempladas al sistema de justicia civil solucionarían buena parte de los problemas que fundamentan la pretensión. Así, por una parte, hay quienes son escépticos de los presuntos beneficios de los tribunales especiales, argumentando que estos atomizan nocivamente la actividad jurisdiccional, debilitan el equilibrio entre los poderes del Estado y que se apartan de la independencia e imparcialidad esenciales para el adecuado funcionamiento de la justicia ordinaria. ${ }^{43}$

Sin ánimo de profundizar en esta discusión en el presente trabajo, se aprecia que este tipo de críticas encuentra buenos contraargumentos cuando se trata de defender la conveniencia de los tribunales societarios especializados. En primer lugar, en cuanto a la atomización de la actividad jurisdiccional, cabe recordar que el legislador ha optado tradicionalmente por apartar la resolución de conflictos societarios de la esfera de la justicia ordinaria, haciendo los conflictos societarios, en general, materia de arbitraje forzoso. Por lo mismo, la implementación de estos tribunales no sustraería de los tribunales ordinarios la resolución de un tipo de conflictos que actualmente se le encuentre encomendada de forma preferencial o excluyente, o bien que en la práctica se sometan regularmente a su conocimiento. Luego, en lo referido a un supuesto desequilibrio entre los poderes del Estado y afectación de la independencia e imparcialidad esencial para la adecuada administración de justicia, debe tenerse en cuenta que la implementación de estos tribunales especiales fuera de la estructura del Poder Judicial (al menos en una primera etapa) en nada obsta a su vinculación con el mismo. Así, no sólo es posible sino de la mayor relevancia que se instaure una revisión posterior (aunque limitada) por los tribunales superiores de justicia, en la forma en que, por ejemplo, opera la "reclamación" contemplada en el Decreto Ley 211, en virtud de la cual la Corte Suprema puede revisar actuaciones realizadas por el Tribunal de Defensa de la Libre Competencia. En este sentido, el profesor Arturo Fermandois, refiriéndose a propuestas

${ }^{43}$ Uno de los más connotados exponentes de este tipo de críticas ha sido Milton Juica, ex presidente de la Corte Suprema. Ver "Tribunales especiales: ijusticia a la carta o eficiencia técnica?, El Mercurio, 4 de marzo de 2011. Disponible en http://www.elmercurio.com/legal/movil/detalle.aspx?Id=900219\&Path=/0D/BC/. 
para una reforma constitucional, destacaba en 2016 la necesidad de resguardar la independencia de los tribunales especializados (sea que se les ubique dentro o fuera del Poder Judicial), la importancia de rescatar el perfil técnico de sus decisiones y, en cuanto a la revisión de las mismas, proponía "configurar un sistema en que la revisión de lo fallado por los tribunales especializados se conduzca mediante recursos o reclamaciones con naturaleza de casación; esto es, infracciones de derecho que influyan en lo dispositivo de la sentencia o que representen quebrantos al debido proceso". ${ }^{44}$ Esta reclamación de casación, en opinión de Fermandois, cumple una función de "unificador de jurisprudencia, control de abusos procesales que cometan los reguladores, o (de) afectación a derechos fundamentales de las partes", y es consistente con la revisión judicial que se desprende del artículo 38 de la Constitución Política de la República. ${ }^{45}$ Asimismo, las nuevas cortes podrían desarrollar y mantener estrechas relaciones con el Poder Judicial por vía de acuerdos de cooperación y capacitación conjunta, así como mediante la participación del Poder Judicial en el nombramiento de sus jueces.

Por otra parte, críticas que apuntan a la conveniencia de mejorar las condiciones para la resolución de conflictos en la justicia ordinaria -incluyendo, por medio de la reforma procesal civil— en lugar de implementar tribunales especiales, se encuentran también con persuasivos argumentos para el caso de las cortes societarias especializadas. Si bien la implementación exitosa de la reforma procesal civil podría solucionar, al menos parcialmente, problemas asociados a la celeridad, inmediatez e impulso procesal requerido para una resolución conveniente de los conflictos societarios, nada parece indicar que se solucionarían los problemas asociados a la falta de experiencia en la resolución de tales disputas; cada vez más sofisticadas y demandantes de conocimientos multidisciplinarios. Tal sofisticación y multidisciplina no justifican el recurrir constantemente a peritos, puesto que se asocian a patrones que se repetirán en el tiempo. Es más, ambas características son fundamentos principales para la especialización. En opinión de Gilson y Schwartz, lo que permite desarrollar experiencia judicial en

${ }^{44}$ Arturo Fermandois, "Propuesta inicial sobre régimen constitucional: la academia y el cambio constitucional en Chile", en Propuestas constitucionales, editado por Lucas Sierra (Santiago: Centro de Estudios Públicos, 2016), 187-188.

${ }^{45}$ Ibídem, 188. 
materia societaria es justamente contar con jueces experimentados en asuntos de negocios y casos sometidos a su conocimiento que caen en patrones limitados y repetitivos. ${ }^{46}$

\subsection{Reglas procesales}

En tercer lugar, la implementación exitosa de un sistema de control ex post requiere de celeridad y una interacción fluida entre las partes $y$ el tribunal. Para ello se hacen necesarias reglas procesales que privilegien la eficacia y la eficiencia por sobre la regulación extenuante y restrictiva de cada una de las etapas del juicio. Medidas que podrían ayudar a estos objetivos serían destrabar la notificación y comparecencia de las partes (permitiendo, por ejemplo, la comparecencia de los intervinientes por medios audiovisuales), proveer una plataforma digital de comunicación entre el juez y los intervinientes (incluyendo para presentaciones de las partes y resoluciones del tribunal), facilitar la acumulación de procedimientos relacionados, hacer más expedito el flujo de información entre distintas reparticiones públicas (haciendo uso de las herramientas que brindan las nuevas tecnologías, incluyendo, eventualmente, blockchain) y, en general, dotar al juez experto de un nivel de discrecionalidad suficiente, de manera que, en ocasiones justificadas, pueda modificar las formalidades previstas como regla general en pos de una mejor y más pronta resolución del conflicto. ${ }^{47}$ Una variedad amplia de alternativas para hacer efectivas medidas precautorias (de ma-

46 Gilson y Schwartz, "Constraints on Private", 21. A mayor abundamiento, en opinión de estos autores, las competencias requeridas para que los jueces puedan evaluar correctamente transacciones societarias depende de su habilidad para evaluar negocios particulares. Dichas competencias pueden agruparse en las siguientes categorías: "(i) pericia en interpretar lenguaje contractual, (ii) pericia en evaluar evidencia, especialmente en el contexto de juicios, (iii) pericia en inferir ex ante resultados intentados a partir de resultados obtenidos, y (iv) experiencia con la industria y los tipos de transacciones que se presentan al conocimiento de la corte". Agregan que esta última categoría generalmente no existirá en las cortes generalistas (Gilson y Schwartz, "Constraints on Private", 30-31).

${ }^{47}$ En la misma línea, la incorporación de la sociedad por acciones en el marco societario chileno (Ley 20.190, de 2007) fue un gran paso hacia la desformalización, permitiendo obviar la constitución por escritura pública (sin perjuicio de la intervención de un notario), requiriendo tan sólo un accionista (con amplia libertad para transferir la propiedad) y flexibilizando la aptitud de las partes para acordar los términos de su asociación. 
nera consistente con el precedente latinoamericano, según se expondrá más adelante) facilitaría también el mejor desempeño de un marco en el que predominen medidas de control ex post.

Consistente con lo anterior, el conocimiento especializado y la celeridad que es menester para que la vía judicial sea una forma atractiva de resolución de conflictos societarios requiere que cualquier instancia de revisión, si la hubiera, se rija también por los principios de especialidad, eficacia y eficiencia. La supuesta falta de experiencia del sistema judicial en la resolución de conflictos societarios, causada por una falta de oportunidades para que los tribunales ordinarios adquieran un nivel de experiencia deseable, repercute también en la aptitud de los tribunales superiores de justicia para resolver acertadamente las disputas relacionadas con dichos conflictos. Sobreponerse a esta falta de experiencia en una segunda instancia regular - aun con mayores índices de litigiosidad - tomaría un tiempo considerable y podría arriesgar el éxito de un nuevo sistema de resolución de conflictos societarios. Asimismo, los fines perseguidos con resoluciones expeditas en la primera fase del proceso se verían afectados si se tramitara la revisión de las sentencias de primera instancia en la misma forma que la de los procedimientos civiles ordinarios. En vistas de lo anterior, el legislador podría considerar que las sentencias de los tribunales societarios especializados (i) estén sujetas a instancias de revisión limitadas en sede ordinaria, más en la forma de casación que de apelación (de manera equivalente a lo que ocurre con los laudos arbitrales), de acuerdo con lo antes sugerido, o (ii) que se establezca una instancia de revisión especializada que también se rija por los principios de eficacia y eficiencia. Optar por la segunda alternativa puede otorgar mayores garantías a los potenciales usuarios, y de tal forma servir de incentivo para que sometan sus contiendas al nuevo sistema, pero los altos costos que requeriría (en infraestructura, así como en recursos humanos y materiales) hacen más prudente favorecer la alta calificación de los jueces de primera instancia y una revisión posterior limitada en sede ordinaria. ${ }^{48}$

${ }^{48}$ Una eventual dependencia de la Comisión para el Mercado Financiero por parte de los tribunales especializados en materia societaria en nada obstaría a que existan instancias de revisión en sede ordinaria de lo fallado por ellos. De manera equivalente ocurre, por ejemplo, con el Tribunal de Defensa de la Libre Competencia (como ya se ha indicado), los Tribunales Tributarios y Aduaneros, los Tribunales Ambientales y los demás tribunales especiales que, sin ser parte de la estructura administrativa del Poder Judicial, están sujetos a su supervigilancia directiva, correccional y económica, ejercida a través de la Corte Suprema. 


\subsection{Políticas públicas}

Un modelo basado en estándares requiere también de políticas públicas que entreguen los incentivos adecuados para que los accionistas que estimen haber sido lesionados en sus derechos procedan a demandar. Así, deben estudiarse cuidadosamente las mecánicas y los requisitos bajo los cuales puede iniciarse una acción derivativa ${ }^{49}$ y otras que permitan a las distintas partes del contrato de sociedad u otros interesados, de ser el caso, hacer valer sus derechos, de manera que disminuyan las barreras para que persigan la resolución de conflictos societarios por la vía judicial.

Con respecto a la acción derivativa, en particular, se ha planteado que la forma en que la ley ordena la distribución de las costas judiciales impone obstáculos relevantes para que los accionistas minoritarios demanden en sede judicial ante el incumplimiento de deberes fiduciarios de los administradores sociales o por otras pérdidas irrogadas al patrimonio de la sociedad. Lo anterior porque, si bien el artículo 133 bis de la Ley sobre Sociedades Anónimas dispone que las costas a que hubiere lugar serán pagadas a el o los accionistas demandantes (y no a la sociedad), en la mayoría de los casos, estos últimos suelen asumir de manera individual las costas del juicio; aun cuando el eventual recupero aumente el patrimonio social y así sea compartido con los demás accionistas de la sociedad. Según las reglas de procedimientos civiles, incluso cuando prospere la acción del minoritario, éste únicamente podrá acceder al reembolso de las costas judiciales en la medida en que el demandado resulte totalmente vencido y siempre que la defensa no haya tenido motivo plausible para litigar. ${ }^{50}$ La evidencia demuestra que los tribunales nacionales han sido reticentes a otorgar condenas en costas. ${ }^{51}$ Más todavía, para el caso en que se cumplieran ambos supues-

${ }^{49}$ Esta acción, consagrada en el artículo 133 bis de la Ley sobre Sociedades Anónimas, es aquélla en virtud de la cual uno o más accionistas se subrogan en la posición de la compañía para exigir la reparación de los ilícitos cometidos por sus directores, gerentes u otros en perjuicio de la misma.

${ }^{50}$ Ver artículo 144 del Código de Procedimiento Civil.

${ }^{51}$ Según concluyen Núñez y Pardow, en base a un estudio de 447 casos de responsabilidad extracontractual ante la Corte Suprema entre los años 2005 y 2006, al 78 por ciento de los demandantes les fue negada la condena en costas y, en consecuencia, debieron soportar todos los gastos relacionados con el juicio. En el tiempo transcurrido entre la fecha del estudio y la de este artículo, no hay motivos para pensar que esta proporción haya variado considerablemente (ver David Núñez y Diego Pardow, “¿Por qué no demandan los accionistas? El problema de las costas en la acción derivativa", Estudios Públicos 118 (2010): 248). 
tos y el tribunal condene en costas a la parte vencida, generalmente las costas reguladas y tasadas por el tribunal serán menores a las realmente incurridas por la parte. Como consecuencia, si el accionista demandante se ve obligado a soportar las costas judiciales en solitario, le resultará atractivo litigar exclusivamente en la medida en que tenga un cierto porcentaje relevante de participación en la compañía (que fácilmente excederá el 5 por ciento de participación social que la ley exige para tener legitimación activa) o, como lo plantean más precisamente Núñez y Pardow, "cuando su porcentaje de participación accionaria supere el porcentaje que las costas representan en la suma que espera obtener como condena". ${ }^{52}$ De tal forma, el accionista se beneficiaría por el exceso de la mayor valorización de su participación social por sobre los costos que eventualmente soportará en solitario por la acción judicial impetrada.

En consecuencia, para que la acción derivativa consagrada en la ley sea funcional a los fines que está llamada a cumplir (protección de los accionistas minoritarios en pos de mercados más transparentes y eficientes) se requiere mejorar la capacidad del accionista demandante de traspasar las costas judiciales a un tercero. Ello podría lograrse por la vía de fomentar un rol más activo de la Comisión para el Mercado Financiero en la interposición de acciones que apunten a la protección de accionistas minoritarios (de forma semejante al rol que tiene el Servicio Nacional del Consumidor, constituyendo un traspaso de costos a la autoridad) o bien contemplando una excepción a las reglas ordinarias para la distribución de las costas judiciales, dejándolas de cargo del demandado vencido (aun cuando no sea enteramente vencido o haya existido motivo plausible para litigar) o bien de la compañía (y, en consecuencia, de todos los accionistas a prorrata de su participación $)^{53}$. La elección de cualquiera de estas alternativas debe incluir un análisis desde el prisma de política pública, especialmente en lo que se refiere a

52 Ibídem, 249-250.

${ }^{53}$ Esta solución no es ajena a nuestro derecho. Así, por ejemplo, en materia de quiebras e insolvencia, las costas judiciales que se causen en el interés general de los acreedores constituyen un crédito de primera clase (artículo 2472 del Código Civil), el agente oficioso es asistido por un derecho de reembolso (artículo 2290 del Código Civil) y lo mismo el comunero que incurre en gastos para el beneficio de la comunidad (artículo 2307 del Código Civil) (Núñez y Pardow, “¿Por qué no demandan?", 233 y 275). 
la conveniencia de una mayor intervención estatal en asuntos de índole privada. $^{54}$

En paralelo, podría considerarse el fomento de acciones de clase como un mecanismo de hacer frente a la apatía racional que afecta a ciertos accionistas minoritarios (motivada, en parte, por los costos de transacción asociados a accionar junto con un grupo considerable de personas). Especialmente en países de tradición jurídica anglosajona, las acciones de clase suelen ser impulsadas por una industria de abogados litigantes que buscan transigir con los demandados y cobrar de las resultas sus honorarios. El aumento de litigación oportunista ligada a estas acciones podría enfrentarse con instancias de pronunciamiento sobre la admisibilidad de la demanda o requiriendo aprobación judicial previa para que los demandantes derivativos puedan transigir. ${ }^{55}$

A lo anterior debe sumarse un marco de regulación y supervisión de los inversionistas institucionales que impulse que éstos persigan la actuación contraria a derecho de los accionistas mayoritarios y administradores de las empresas en las que invierten. Este marco requiere una revisión de cómo los resultados del litigio se considerarán en las estructuras de comisiones percibidas por tales inversionistas. Por otra parte, el propósito de desincentivar la omisión injustificada de inversionistas institucionales en el ejercicio de acciones societarias (incluyendo la acción derivativa) podría lograrse mediante la amenaza creíble de sanciones relevantes impuestas por el regulador competente. Sin embargo, esta alternativa requiere, nuevamente, ponderar de antemano la deseabilidad de la intervención estatal en la esfera privada. ${ }^{56}$

\section{EL PRECEDENTE LATINOAMERICANO}

El osado camino de comenzar a dejar atrás las reglas y apuntar hacia un sistema de derecho societario que incorpore estándares cuenta con un precedente relevante en Latinoamérica. Colombia, con la dictación de la Ley 1.258, de 2008 (la "Ley SAS"), fue un pionero en el intento. La ley en cuestión, cuya finalidad principal es regular la

\footnotetext{
${ }^{54}$ Ibídem, 274-275.

55 Ibídem, 276.

${ }^{56}$ Ibídem, 276-277.
} 
sociedad por acciones simplificada (símil cercano a la sociedad por acciones chilena), consagró legislativamente: (i) estándares específicamente diseñados para abordar conflictos entre accionistas mayoritarios y minoritarios,${ }^{57}$ incluyendo las figuras de la desestimación de la personalidad jurídica y el abuso del derecho a voto, ${ }^{58}$ y (ii) la resolución de conflictos societarios por la Superintendencia de Sociedades (equivalente a la Comisión para el Mercado Financiero de Chile) mediante un trámite de proceso verbal sumario, a falta de disposición en los estatutos sociales que ordene someter la controversia a la decisión de árbitros o de amigables componedores.

En virtud de esta nueva concepción del derecho societario, el legislador colombiano otorgó a la Superintendencia de Sociedades "facultades jurisdiccionales para conocer sobre toda clase de controversias de naturaleza societaria, incluidas aquellas que se presenten entre accionistas, entre éstos y la sociedad o entre éstos y los administradores". 59

57 José Miguel Mendoza, "The Colombian SAS and the Transition from Rules to Standards", en The Colombian Simplified Corporation: A Comparative and Functional Perspective, editado por Francisco Reyes (Bogotá: Editorial Temis, 2018), 105.

${ }^{58}$ La consagración legal de estas figuras en la forma de estándares es clara de la redacción amplia de los artículos respectivos en la Ley 1.258. El artículo 42, referido a la desestimación de la personalidad jurídica, dispone en su parte relevante que "cuando se utilice la sociedad por acciones simplificada en fraude a la ley o en perjuicio de terceros, los accionistas y los administradores que hubieren realizado, participado o facilitado los actos defraudatorios, responderán solidariamente por las obligaciones nacidas de tales actos y por los perjuicios causados" (el énfasis es nuestro). En el mismo espíritu, el artículo 43, referido al abuso del derecho a voto, dispone en su parte relevante que "los accionistas deberán ejercer el derecho de voto en el interés de la compañía. Se considerará abusivo el voto ejercido con el propósito de causar daño a la compañía o a otros accionistas o de obtener para sí o para una tercera ventaja injustificada, así como aquel voto del que pueda resultar un perjuicio para la compañía o para los otros accionistas. Quien abuse de sus derechos de accionista en las determinaciones adoptadas en la asamblea, responderá por los daños que ocasione, sin perjuicio que la Superintendencia de Sociedades pueda declarar la nulidad absoluta de la determinación adoptada, por la ilicitud del objeto" (el énfasis es nuestro). Dispone además el referido artículo 43 que las acciones correspondientes al abuso del derecho a voto pueden ejercerse tanto en los casos de abuso de mayoría, como en los de minoría y de paridad, reconociendo que también los accionistas minoritarios pueden aprovecharse injustificadamente de las prerrogativas que les entrega la ley (Ley 1.258, del 5 de diciembre de 2008, "Por medio de la cual se crea la sociedad por acciones simplificada", República de Colombia).

${ }^{59}$ Superintendencia de Sociedades de Colombia, "Guía de litigio societario. Delegatura para Procedimientos Mercantiles", septiembre de 2016. Disponible en https://issuu.com/dpm20/docs/gui_a_de_litigio_societario/8. 
Estas facultades jurisdiccionales fueron puestas en práctica a través de la Delegatura para Procedimientos Mercantiles (la "Delegatura"). El foro, una corte especializada en derecho societario creada en 2012 y dependiente de la Superintendencia de Sociedades, cuenta con amplias facultades para conocer acerca de los más diversos asuntos de índole societaria. La jurisdicción de la Delegatura, inicialmente concebida para conocer conflictos societarios relacionados con sociedades por acciones simplificadas, se extiende en la actualidad a "cualquier tipo de controversia que se presente entre sujetos que tengan la legitimación jurídica e interés económico para hacer efectivas reglas de derecho societario colombiano en un proceso judicial"60 (incluyendo, salvo algunas excepciones, aquellas que se susciten en relación con sociedades que hacen oferta pública de sus acciones). La jurisprudencia de la Delegatura incluye conflictos sobre el abuso del derecho a voto, régimen de administración, pactos de accionistas, causales de disolución y liquidación, suscripción y transferencia de acciones y cuotas sociales, vicios en el funcionamiento de los órganos sociales, desestimación de la personalidad jurídica, exclusión de socios, valoración de sociedades, y falsedades en actas, entre otros. ${ }^{61}$ Además, la Delegatura puede decidir sobre la aplicación de medidas cautelares o precautorias — nominadas o innominadas - , entendiendo por tales aquellas que son razonables para la protección del objeto del litigio (a modo de ejemplo, orden de no celebrar negocios jurídicos por fuera del giro ordinario de los negocios, orden de entregar copias de los libros de comercio de una compañía, orden de no celebrar una junta de accionistas, orden de reconstituir el patrimonio de una sociedad, orden de suspender la elección de miembros de la junta directiva y del representante legal, y orden de suspender la venta de los principales activos de una compañía). ${ }^{62}$

Los resultados han sido positivos. En sus primeros años de funcionamiento, el número de demandas presentadas por los usuarios se

${ }^{60}$ Ibídem.

${ }^{61}$ Ver "Jurisprudencia Delegatura para Procedimientos Mercantiles", Superintendencia de Sociedades de Colombia. Disponible en https://www.supersociedades. gov.co/delegatura_mercantiles/Normatividad/Paginas/Busqueda-Jurisprudencia-delegatura-procedimientos-mercantiles.aspx (accedida el 27 de noviembre de 2018).

${ }^{62}$ Superintendencia de Sociedades de Colombia, "Preguntas frecuentes de los usuarios de la Delegatura para Procedimientos Mercantiles". Disponible en https:// www.supersociedades.gov.co/Servicio_Ciudadano/Documents/preguntas\%20frecuente $\% 20$ mercantiles.pdf. 
incrementó en 500 por ciento respecto del régimen anterior. En promedio, la corte recibe alrededor de dos demandas al día, lo que, según las autoridades colombianas, no ha generado congestión gracias a un eficiente proceso de gestión de causas. ${ }^{63} \mathrm{La}$ dictación de sentencias tarda en promedio cinco meses, ${ }^{64}$ lo que resulta asombroso al comparar con lo que tarda en promedio la resolución de disputas comerciales ante los tribunales ordinarios de primera instancia en Colombia (43 meses), Latinoamérica y el Caribe (26 meses) e incluso los países de altos ingresos de la OCDE (19 meses) ${ }^{65,66}$ En un esfuerzo por acotar los plazos totales que tarda obtener sentencias ejecutoriadas, el estatuto colombiano sólo permite la apelación (ante tribunales ordinarios) de las sentencias dictadas por la Delegatura en casos limitados. Asimismo, la Corte Constitucional de Colombia puede revisar dichas sentencias en procedimientos breves de tutela, destinados a hacer valer las garantías constitucionales. ${ }^{67}$

Junto con las eficiencias antes indicadas, las cortes societarias colombianas cumplen la función de construir jurisprudencia y orientar, en base a precedentes, sobre el comportamiento esperado de quienes intervienen en relaciones societarias. Esta experiencia institucional es plasmada en publicaciones periódicas a cargo de la Superintendencia de Sociedades, en las que se ponen a disposición del público (en su página

63 "Introducción a la nueva corte societaria", Superintendencia de Sociedades de Colombia (accedido el 20 de noviembre de 2018), https://www.supersociedades. gov.co/delegatura_mercantiles/Paginas/Objetivo.aspx (accedido el 20 de noviembre).

${ }^{64}$ Ibídem.

65 World Bank Group, Doing Business 2019: Training for Reform. Economy Profile: Colombia (Washington DC: International Bank for Reconstruction and Development/The World Bank, 2019), 48. Disponible en http://www.doingbusiness. org/content/dam/doingBusiness/country/c/colombia/COL.pdf.

${ }^{66}$ Según José Miguel Mendoza, abogado colombiano encargado de poner en marcha estos tribunales especializados, en los que además actuó como juez, después de tan sólo siete años de la creación de la Delegatura esta corte ha emitido más de mil decisiones judiciales sobre toda clase de asuntos societarios. Dicha producción jurisprudencial sería comparable a los resultados acumulados por Colombia durante la segunda mitad del siglo XX (José Miguel Mendoza, "La principal innovación de la Ley SAS", Ámbito Jurídico, 15 de agosto de 2018. Disponible en https://www. ambitojuridico.com/noticias/columnista-impreso/sociedades-y-economia-solidaria/ la-principal-innovacion-de-la-ley-sas).

${ }^{67}$ Mendoza, "The Colombian SAS”, 104-105. 
web, de manera gratuita y separados por materia) los pronunciamientos más relevantes de la Delegatura.

El nuevo sistema colombiano de resolución de controversias societarias, incluyendo la calidad de sus sentencias, ha sido reconocido por la Comisión de las Naciones Unidas para el Derecho Mercantil Internacional, la que ha indicado que "el amplio acervo de casos que ha resuelto la nueva corte, sumado a la calidad técnica de sus decisiones y la celeridad con la que se tramitan los procesos a su cargo, da cuenta del éxito que ha tenido este importante foro para la resolución de conflictos empresariales". 68

El aumento de litigios societarios, una consecuencia esperada del (así llamado) nuevo régimen colombiano de justicia empresarial, no debe ser motivo de inquietud en la transición propuesta hacia los estándares. Por el contrario, mayores índices de litigiosidad son habituales en países que, como Colombia —y también Chile_-, han comenzado a recorrer el camino de la industrialización. ${ }^{69}$

\section{CONCLUSIÓN}

La adecuada protección de los inversionistas representa un requisito esencial para el desarrollo de las naciones. La alta concentración de la propiedad accionaria en Chile genera riesgos de que los accionistas mayoritarios, abusando de las prerrogativas que les otorga su posición, expropien a los minoritarios. Esta conducta no sólo es nociva para los inversionistas lesionados (incluyendo, eventualmente, inversionistas institucionales) y la sociedad en cuestión, sino que también atenta contra la transparencia y eficiencia de los mercados. La incertidumbre sobre si los minoritarios serán o no víctimas de expropiación a manos de los mayoritarios genera problemas de selección adversa y, así, aumentan los costos del capital, dificulta el desarrollo de los mercados, y limita la capacidad del país para atraer inversión extranjera.

${ }^{68}$ Superintendencia de Sociedades de Colombia, "El buen gobierno en práctica: cuatro años de gestión de la supersociedades". Disponible en https://www.supersociedades.gov.co/Historial\%20de\%20Noticias/Presentacion-Rendicion-Cuentas20-agosto-2014.pdf (accedido el 10 de noviembre de 2018).

${ }^{69}$ Mendoza, "La principal innovación". 
La legislación chilena implementa un sistema de control de las actuaciones societarias ex ante - vale decir, antes de que ocurra la conducta-, el que privilegia prohibiciones y reglas de autocumplimiento; a diferencia de un sistema de control ex post, el que se encuentra basado en estándares. Esta opción fue tomada en consideración a la estructura de capital de las sociedades nacionales y, presumiblemente, a una herencia de escasa experiencia institucional en la resolución de conflictos societarios. A las puertas del desarrollo, considerar la transición hacia un sistema de derecho societario mixto que favorezca el uso de estándares y, además, conserve reglas útiles, contribuiría a mejorar las condiciones ofrecidas por el país para el comercio. Este sistema permitiría otorgar mayores certezas a emprendedores e inversionistas, junto con reducir ineficiencias que son consecuencia natural de los sistemas basados primordialmente en prohibiciones y reglas de autocumplimiento. El mismo debe apuntar a proteger con idéntico vigor tanto a los accionistas minoritarios, como a los mayoritarios y administradores sociales que han sido vulnerados en sus derechos o perjudicados injustamente.

La transición exitosa hacia un sistema que fomente el control de transacciones ex post supone cuatro pilares fundamentales: el diseño e implementación de estándares adecuados; la creación de tribunales especializados en materias societarias; reglas del proceso flexibles, que permitan al juzgador actuar en pos de la mejor y más expedita resolución del conflicto; y políticas públicas que provean los incentivos correctos.

El camino a seguir — no exento de dificultades - ya fue emprendido por otra nación latinoamericana. Los buenos resultados obtenidos, así como el reconocimiento de organismos internacionales respecto de tal sistema, hacen pensar que seguir un sendero parecido es no sólo atractivo, sino también posible para Chile.

Alcanzar una reputación de excelencia en la resolución de conflictos societarios, mediante la transición exitosa a un sistema de control de transacciones ex post, ayudaría a reivindicar el derecho societario como instrumento de política económica, favoreciendo un mayor dinamismo de la actividad empresarial interna. Asimismo, contribuiría al posicionamiento y consolidación de Chile como centro financiero regional, mejorando su atractivo para inversionistas internacionales. 
Junto con los efectos antes señalados, la evolución hacia un sistema que incorpore en mayor grado estándares, representaría una sofisticación del derecho societario nacional. Así, tendría efectos entre estudiantes, académicos y abogados practicantes, potenciando el interés por esta apasionante rama del derecho. Para ello se requiere reformular la enseñanza del derecho societario, haciendo esfuerzos por instruir y entrenar a los estudiantes en el uso del razonamiento crítico y de conocimientos multidisciplinarios para resolver situaciones complejas. Quizás así se podría alejar el foco de los cursos de derecho societario de cuestiones relativamente periféricas, como los límites del objeto de la sociedad y su duración, para discutir sobre asuntos con implicancias prácticas más vigentes y relevantes, como el abuso de la posición del mayoritario, el tratamiento adecuado de los conflictos de interés, y la ejecución de acuerdos nominados e innominados entre socios, incorporando además la conducción de juicios simulados.

\section{BIBLIOGRAFÍA}

Aran, Yifat. "From Delaware to Israel: Evaluating Israel's Quasi Experiment of a Specialized Corporate Court". Disponible en SSRN (2015). http://dx.doi. org/10.2139/ssrn.2619916.

Black, Bernard \& Reinier Kraakman. “A Self-Enforcing Model of Corporate Law”. Harvard Law Review 109 (1996): 1911-1982.

Donelli, Marcelo, Borja Larraín \& Francisco Urzúa. "Ownership Dynamics with Large Shareholders: an Empirical Analysis". Journal of Financial and Quantitative Analysis 48 (2013). https://ssrn.com/abstract=1966011.

Dworkin, Ronald M. "The Model of Rules". The University of Chicago Law Review 35 (1967): 14-46.

El Mercurio. "Tribunales especiales: ¿justicia a la carta o eficiencia técnica?" 4 de marzo de 2011. http://www.elmercurio.com/legal/movil/detalle. aspx?Id=900219\&Path=/0D/BC/.

Enrione, Alfredo. "Gobierno corporativo: un imperativo de hoy". En Directorio y gobierno corporativo: el desafio de agregar valor en forma sostenida, editado por Alfredo Enrione, 27-38. Santiago: ESE Business - Universidad de los Andes, 2014.

Fermandois, Arturo. "Propuesta inicial sobre régimen constitucional: la academia y el cambio constitucional en Chile". En Propuestas constitucionales, editado por Lucas Sierra, 181-197. Santiago: Centro de Estudios Públicos, 2016.

Gilson, Ronald J. \& Alan Schwartz. "Constraints on Private Benefits of Control: Ex Ante Control Mechanisms Versus Ex Post Transaction Review”. Yale Law \& 
Economics Research Paper 455; Stanford Law and Economics Olin Working Paper 432; Columbia Law and Economics Working Paper 430; ECGI - Law Working Paper 194/2012. http://dx.doi.org/10.2139/ssrn.2129502.

Gurrea Martínez, Aurelio. "La sociedad por acciones simplificada como paradigma de innovación jurídica: una reflexión sobre la función social de los investigadores de derecho a partir de la experiencia de la SAS en Colombia”. Instituto Iberoamericano de Derecho y Finanzas Working Paper Series 2/2018 (2018). http://dx.doi.org/10.2139/ssrn.3097775.

Gurrea Martínez, Aurelio \& Oliver Orton. "Hacia un sistema creíble de directores independientes en las sociedades cotizadas latinoamericanas". Instituto Iberoamericano de Derecho y Finanzas Working Paper Series 3/2018 (2018). https://papers.ssrn.com/sol3/papers.cfm?abstract_id=3144054.

Harari, Yuval Noah. Sapiens (New York: Harper Collins, 2015).

Kraakman, Reinier, John Armour, Paul Davies, Luca Enriques, Henry Hansmann, Gerald Hertig, Klaus Hopt, Hideki Kanda, Mariana Pargendler, Wolf-Georg Ringe \& Edward Rock. The Anatomy of Corporate Law: A Comparative and Functional Approach. New York: Oxford University Press, 2017.

Latin America Private Equity \& Venture Capital Association. 2017/2018 Scorecard: The Private Equity and Venture Capital Environment in Latin America. New York: Latin America Private Equity \& Venture Capital Association, 2017. https://lavca.org/wp-content/uploads/2017/06/20172018-Scorecard-FINAL. pdf.

La Porta, Rafael, Florencio Lopez-de-Silanes, Andrei Shleifer \& Robert W. Vishny. "Investor Protection and Corporate Governance". Journal of Financial Economics 58 (2000): 3-27.

. "Law and Finance". Journal of Political Economy 106, n. ${ }^{\circ} 6$ (1998): 11131155 .

Lefort, Fernando. "Ownership Structure and Corporate Governance in Latin America”. Revista Abante 8, n. 1 (2005): 55-84. http://finanzas.udp.cl/paper/ fl17\%20OWNERSHIP\%20STRUCTURE\%20AND\%20CORPORATE\%20 GOVERNANCE\%20IN\%20LATIN\%20AMERICA.pdf.

Mendoza, José Miguel. "El abuso de mayoría en la SAS". En La SAS y su influencia en América Latina, editado por Francisco Reyes, 113-135. Bogotá: Editorial Temis, 2018.

—. "The Colombian SAS and the Transition from Rules to Standards". En The Colombian Simplified Corporation: A Comparative and Functional Perspective, editado por Francisco Reyes, 79-106. Bogotá: Editorial Temis, 2018.

- "La principal innovación de la Ley SAS". Ámbito Jurídico, 15 de agosto de 2018. https://www.ambitojuridico.com/noticias/columnista-impreso/ sociedades-y-economia-solidaria/la-principal-innovacion-de-la-ley-sas.

Núñez, David \& Diego Pardow. “¿Por qué no demandan los accionistas? El problema de las costas en la acción derivativa”. Estudios Públicos 118 (2010): 229-282. 
Reyes Villamizar, Francisco. "Corporate Governance in Latin America: A Functional Analysis". University of Miami Inter-American Law Review 39 (2008): 207-268. https://repository.law.miami.edu/umialr/vol39/iss2/2/.

Saona, Paolo, Pablo San Martín \& Mauricio Jara. "Group Affiliation and Ownership Concentration as Determinants of Capital Structure Decisions: Contextualizing the Facts for an Emerging Economy". Emerging Markets Finance and Trade (2017): 1-18. doi: 10.1080/1540496X.2017.1392850.

Ugarte Vial, Jorge. Pactos sobre transferencia de acciones. Santiago: Editorial Jurídica de Chile, 2016.

World Bank Group. Doing Business 2019: Training for Reform. Economy Profile: Chile. Washington DC: International Bank for Reconstruction and Development/The World Bank, 2019. http://www.doingbusiness.org/content/ dam/doingBusiness/country/c/chile/CHL.pdf.

Doing Business 2019: Training for Reform. Economy Profile: Colombia. Washington DC: International Bank for Reconstruction and Development/The World Bank, 2019. http://www.doingbusiness.org/content/dam/doingBusiness/ country/c/colombia/COL.pdf.

\section{DoCUMENTOS OFICIALES}

\section{Normas}

Código de Comercio. República de Chile.

Código Orgánico de Tribunales. República de Chile.

Ley 18.045, del 22 de octubre de 1981. "Ley de mercado de valores”. República de Chile.

Ley 18.046, del 22 de octubre de 1981. "Ley sobre sociedades anónimas". República de Chile.

Ley 19.705, del 20 de diciembre de 2000. "Regula las ofertas públicas de adquisición de acciones (OPAS) y establece régimen de gobiernos corporativos". República de Chile.

Ley 20.382, del 20 de octubre de 2009. "Introduce perfeccionamientos a la normativa que regula los gobiernos corporativos de las empresas". República de Chile.

Ley 1.258, del 5 de diciembre de 2008. "Por medio de la cual se crea la sociedad por acciones simplificada”. República de Colombia.

\section{Otros documentos}

República de Chile. "Mensaje de la Ley 18.046". 30 de diciembre de 1980. https:// www.bcn.cl/historiadelaley/nc/historia-de-la-ley/7574/.

Poder Judicial de Chile. Memorias Anuales 2013-2017. http://www.pjud.cl/ memorias-anuales. 
- "Poder judicial en números 2018. Cortes de apelaciones Parte 3. Tomo IV". Agosto de 2018. http://www.pjud.cl/documents/10179/11855875/4. Cortes + de + Apelaciones + Parte+III.pdf/a6af25e 0-a59d-40a3-a923dec89304b778? version=1.2.

. "Poder judicial en números 2018. Estadísticas de causas. Tomo I". Agosto de 2018. http://www.pjud.cl/documents/10179/11855875/1.Estadisticas+de+Causas. pdf/6c10b204-4f22-4b13-975c-8416f8ea0be7?version=1.2.

_. "Poder judicial en números. Tomo I. Estadísticas de causas". (Para años 2015 al 2018). Disponible en http://www.pjud.cl/poder-judicial-en-numeros.

Superintendencia de Sociedades de Colombia. "El buen gobierno en práctica: cuatro años de gestión de la supersociedades". 2014. https://www.supersociedades.gov.co/Historial\%20de $\% 20$ Noticias/Presentacion-RendicionCuentas-20-agosto-2014.pdf.

- "Guía de litigio societario. Delegatura para Procedimientos Mercantiles". Septiembre de 2016. https://issuu.com/dpm20/docs/gui_a_de_litigio_ societario/8.

. "Introducción a la nueva corte societaria". https://www.supersociedades. gov.co/delegatura_mercantiles/Paginas/Objetivo.aspx (accedido el 20 de noviembre).

—. "Jurisprudencia Delegatura para Procedimientos Mercantiles". https:// www.supersociedades.gov.co/delegatura_mercantiles/Normatividad/Paginas/ Busqueda-Jurisprudencia-delegatura-procedimientos-mercantiles.aspx

- "Preguntas frecuentes de los usuarios de la Delegatura para Procedimientos Mercantiles". https://www.supersociedades.gov.co/Servicio_Ciudadano/ Documents/preguntas\%20frecuente\%20mercantiles.pdf. EP 